\title{
Non-Trigeminal Nociceptive Innervation of the Posterior Dura: Implications to Occipital Headache
}

\author{
- Rodrigo Noseda, Agustin Melo-Carrillo, Rony-Reuven Nir, Andrew M. Strassman, and $₫$ Rami Burstein \\ Department of Anesthesia, Critical Care and Pain Medicine, Beth Israel Deaconess Medical Center and Harvard Medical School, Boston, Massachusetts \\ 02115
}

Current understanding of the origin of occipital headache falls short of distinguishing between cause and effect. Most preclinical studies involving trigeminovascular neurons sample neurons that are responsive to stimulation of dural areas in the anterior $2 / 3$ of the cranium and the periorbital skin. Hypothesizing that occipital headache may involve activation of meningeal nociceptors that innervate the posterior $1 / 3$ of the dura, we sought to map the origin and course of meningeal nociceptors that innervate the posterior dura overlying the cerebellum. Using AAV-GFP tracing and single-unit recording techniques in male rats, we found that neurons in C2-C3 DRGs innervate the dura of the posterior fossa; that nearly half originate in DRG neurons containing CGRP and TRPV1; that nerve bundles traverse suboccipital muscles before entering the cranium through bony canals and large foramens; that central neurons receiving nociceptive information from the posterior dura are located in $\mathrm{C} 2-\mathrm{C} 4$ spinal cord and that their cutaneous and muscle receptive fields are found around the ears, occipital skin and neck muscles; and that administration of inflammatory mediators to their dural receptive field, sensitize their responses to stimulation of the posterior dura, peri-occipital skin and neck muscles. These findings lend rationale for the common practice of attempting to alleviate migraine headaches by targeting the greater and lesser occipital nerves with anesthetics. The findings also raise the possibility that such procedures may be more beneficial for alleviating occipital than non-occipital headaches and that occipital migraines may be associated more closely with cerebellar abnormalities than in non-occipital migraines.

Key words: cerebellum; cervical; DRG; dura; migraine; neck muscles

\section{Significance Statement}

Occipital headaches are common in both migraine and non-migraine headaches. Historically, two distinct scenarios have been proposed for such headaches; the first suggests that the headaches are caused by spasm or tension of scalp, shoulders, and neck muscles inserted in the occipital region, whereas the second suggests that these headaches are initiated by activation of meningeal nociceptors. The current study shows that the posterior dura overlying the cerebellum is innervated by cervicovascular neurons in C2 DRG whose axons reach the posterior dura through multiple intracranial and extracranial pathways, and sensitization of central cervicovascular neurons from the posterior dura can result in hyper-responsiveness to stimulation of neck muscles. The findings suggest that the origin of occipital and frontal migraine may differ.

\section{Introduction}

Occipital headaches can be a prominent feature of both migraine and non-migraine headaches. One-third of all migraines begin with tenderness of neck and shoulder muscles that gradually develop into a low-grade occipital headache (Liveing, 1873; Kelman, 2005). Occipital headaches are also common in non-

\footnotetext{
Received Aug. 21, 2018; revised Nov. 8, 2018; accepted Dec. 27, 2018.

Author contributions: R.N., A.M.S., and R.B. designed research; R.N. and A.M.-C. performed research; R.N.,

A.M.-C., R.-R.N., A.M.S., and R.B. analyzed data; A.M.S. edited the paper; R.N. and R.B. wrote the paper.

This work was supported by NIH Grants R21-NS090254 (R.N.), R01-NS104296 (R.N.), and R37-NS079678 (R.B.).

The authors declare no competing financial interests.

Correspondence should be addressed to Rodrigo Noseda at rnoseda@bidmc.harvard.edu.

https://doi.org/10.1523/JNEUROSCI.2153-18.2018

Copyright $\odot 2019$ the authors $\quad 0270-6474 / 19 / 391867-14 \$ 15.00 / 0$
}

migraine headaches such as tension-type (Jensen et al., 1993), cervicogenic (Sjaastad and Fredriksen, 2000; Bogduk, 2004), and those associated with Chiari malformation (Watkins, 1969). Current speculations on the cause of occipital headaches often fall short at distinguishing between cause (where it originates) and effect (where it hurts). Traditionally, it has been thought that occipital headache is generated in trigemino-cervical complex neurons that receive nociceptive signals from the intracranial dura, pericranial muscles, and skin at the back of the head (Piovesan et al., 2001; Bartsch and Goadsby, 2002; Bogduk, 2004). According to this scenario, occipital headaches may be initiated by spasms or tension of scalp, shoulders, and neck muscles inserted in the occipital region (Olesen, 1978; Edmeads, 1988), or by irritation of the dura during migraine. Occipital headaches can 
also occur when C2 sensory roots are compressed, irritated, or inflamed (Chouret, 1967). One of the most direct lines of evidence for C2 DRG involvement in occipital headache was described as early as the 1960 s by Kerr (1961) in a report on the occurrence of occipital headache during stimulation of C2 DRG and their nerve roots, an observation confirmed recently by Johnston et al. (2013). The involvement of C2 DRG and its nerve roots in occipital headache is also supported by the frequent elimination of occipital pain and headache following anesthetic blockade of the occipital nerve and its branches (Edmeads, 1988; Sjaastad and Fredriksen, 2000; Paemeleire and Bartsch, 2010; Paemeleire et al., 2010; Palmisani et al., 2013).

To date, most if not all preclinical studies involving trigeminovascular nociception sample central and peripheral neurons that are responsive to stimulation of the dura neighboring large blood vessels (e.g., transverse and superior sagittal sinuses, medial meningeal artery), or cerebral cortex, all located in the anterior $2 / 3$ of the cranium, and the periorbital skin (Welch, 2003; Borsook et al., 2004; Akerman et al., 2011; Vecchia and Pietrobon, 2012; Noseda and Burstein, 2013). Given the above, it is not surprising that little or no information is available regarding the innervation of the posterior dura overlying the cerebellum (Kimmel, 1961; Keller et al., 1985).

To begin elucidating the neural substrate of occipital headache, we sought to map the origin and course of meningeal nociceptors that innervate the posterior $1 / 3$ of the dura overlying the cerebellum, including their cellular origin in C2 and C3 DRGs, neurochemical content, entry points into the skull, and the impact of their activation on central cervicovascular neurons in the spinal cord.

\section{Materials and Methods}

Animals. Fifty-four male Sprague-Dawley rats weighting 250-350 g were used in this study. Experiments were conducted in accordance with NIH guidelines and approved by the Institutional Animal Care and Use Committee at Harvard Medical School and Beth Israel Deaconess Medical Center. Rats were housed in a controlled environment $\left(22^{\circ} \mathrm{C} \mathrm{RT} ; 12 \mathrm{~h}\right.$ light/dark cycle) with ad libitum access to food and water.

Anterograde tracing of C2 DRG neurons innervating the posterior dura. To label the full extent of axons innervating the posterior dura, an adenoassociated viral vector carrying GFP as reporter gene (AAV-GFP) was delivered into C2 DRG. First, rats were anesthetized with methohexital sodium (Brevital; $45 \mathrm{mg} / \mathrm{kg}$, i.p.) to allow endotracheal intubation. Each rat was then mounted on a stereotaxic frame and connected to a gas anesthesia system until the end of the procedure $\left(2.5 \%\right.$ isoflurane in $\mathrm{O}^{2}$, delivered at $100 \mathrm{ml} / \mathrm{min}$ ). End-tidal $\mathrm{CO}_{2}$, respiratory and heart rate, blood oxygen saturation and body temperature were continuously monitored and kept within physiological range. Second, the dorsal skin of the neck was incised at the midline under sterile conditions and muscles were gently pulled aside to visualize the caudal edge of $\mathrm{C} 1$ vertebra. A small, partial laminectomy of $\mathrm{C} 1$ was performed to expose the left C2 DRG. Then, a glass micropipette (tip diameter 5-10 $\mu \mathrm{m}$ ) connected to a microsyringe was attached to a manipulator and loaded with the viral vector. Two injections of $5 \mu \mathrm{l}(1 \mu \mathrm{l} / \mathrm{min}$ ) of either (1) AAV-GFP (serotype 2; $7 \times 10^{12}$ genome copies/ml; HGTI) or (2) AAV2/5CMVeGFP (VVC-U of Iowa-138) were performed into the $\mathrm{C} 2$ ganglion using a microinjector (Micro4, WPI). After viral vector delivery, wounds were sutured, disinfected, and postsurgical analgesics provided (Meloxicam SR, $4 \mathrm{mg} / \mathrm{kg}$, s.c.; Zoopharm). Animals were allowed to recover from anesthesia and put back into their cages for $21 \mathrm{~d}$ to allow efficient viral transduction and expression of GFP.

Retrograde labeling from the posterior dura to C2-C4 DRGs. The purpose of these experiments was to confirm the anterograde tracing findings and identify the type, location, and neurochemical content of the neurons innervating the posterior dura. For this procedure, rats were anesthetized, mounted on a stereotaxic frame, and monitored as described above. Neck muscles inserted into the superior nuchal line of the occipital bone were incised and displaced downward using a cotton tip to perform a small craniotomy on the left side of the vertical portion of the occipital bone, immediately below the suture formed between the occipital and interparietal bones. A piece of gel foam soaked in FluoroGold (FG; $2 \%$ in $\mathrm{dH}_{2} \mathrm{O}$; Fluorochrome) was placed on the dura and gently pushed under the occipital bone. To avoid leaking of the tracer from the epidural space, sterile bone wax was applied to cover the skull opening and was secured by gluing on top a portion of surrounding subcutaneous tissue with Vetbond (3M). Wounds were sutured and disinfected, analgesics provided, and animals replaced into their cages for $3 \mathrm{~d}$.

Tissue collection and processing. Twenty-one days after administration of anterograde viral vectors and $3 \mathrm{~d}$ after administration of retrograde tracers, rats were deeply anesthetized with an overdose of pentobarbital sodium (150 mg/kg, i.p.) and perfused with $200 \mathrm{ml}$ heparinized saline followed by a fixative solution containing $400 \mathrm{ml}$ of paraformaldehyde $(4 \%)$ and $20 \mathrm{ml}$ of picric acid (1.3\%) in $0.1 \mathrm{M}$ PBS. For the anterograde labeling study, C2 DRG and large areas of the dura were collected for analysis, including the (1) anterior dura, covering the cerebral cortex from the olfactory bulb to the transverse sinus; (2) posterior dura overlying the cerebellum from the caudal border of transverse sinus to the obex; (3) spinal dura, overlying the spinal cord from the obex to C5 segment of the spinal cord; (4) lateral dura, covering the cerebral cortex along the temporal aspect of the brain; and (5) tentorial dura, between occipital cortex and cerebellum. Collected portions of the dura were briefly mounted on slides and visualized under the fluorescent microscope to confirm the presence of GFP-positive fibers. We also collected large blood vessels of the posterior dura and neck muscles to analyze their relationship to GFP-labeled fibers (if present). For the retrograde labeling study, we collected the area of the dura where the tracer was applied to confirm its integrity and spread, as well as C2-C4 DRGs and trigeminal ganglion (TG) for immunofluorescence and further analysis.

Immunofluorescence. Dura sections containing GFP-labeled fibers were soaked in PBS for immunofluorescence (IF). C2 DRGs from animals exhibiting GFP labeling in the dura (anterograde study) and those from animals exhibiting FG labeling in C2/3 DRGs (retrograde study) were cryoprotected in $30 \%$ sucrose PBS for $48 \mathrm{~h}$, frozen, and cut into serial transversal sections ( $20 \mu \mathrm{m}$ thick) using a cryostat (Leica). DRG Sections were thaw-mounted onto gelatin-coated glass slides and processed for IF. Free-floating whole-mount dura and C2 DRG sections were pre-incubated at room temperature in PBS containing 2\% bovine serum albumin and $1 \%$ Triton X-100 for $1 \mathrm{~h}$, followed by incubation at $4^{\circ} \mathrm{C}$ for $48 \mathrm{~h}$ with primary antibodies against CGRP (rabbit anti-CGRP; 1:5000; Millipore, catalog \#PC205L; RRID:AB_2068524) or TRPV1 (rabbit antiTRPV1; 1:500; Alomone Labs, catalog \#ACC-030; RRID:AB_2313819). Tissue was rinsed in PBS and incubated for $2 \mathrm{~h}$ at room temperature with the corresponding fluorescent secondary antibody [1:500; AlexaFluor 488 or 594; ThermoFisher Scientific, catalog \#A-11008 (RRID: AB_143165) and catalog \#A-11037 (RRID:AB_2534095)] against the Igs of the species in which the primary antibody was raised. Fluorescent labeling of C2 DRG cells with Isolectin B4 $(20 \mu \mathrm{g} / \mathrm{ml}$; Vector Laboratories, catalog \#FL-1201; RRID:AB_2314663) was also performed. Tissue was rinsed, stained for DAPI $(1 \mu \mathrm{g} / \mathrm{ml}$; ThermoFisher Scientific, catalog \#62248) and coverslipped with fluorescent mounting media Fluoromount (Sigma-Aldrich, catalog \#F4680) before imaging.

Digital imaging of dural innervation and C2 DRG cell bodies. Digital imaging of labeling in different dura sections, C2 DRGs, nerve fibers, and blood vessels was performed on a fluorescence scanning microscope (Leica DM5500) that compile $1-1.5-\mu \mathrm{m}$-thick scans using a $z$-stacking software application (LASX, Leica). Labeling of CGRP, TRPV1, and IB4 was detected by excitation/emission at 551/624 nm (red). GFP and DAPI labeling were detected by excitation/emission at $455 / 520 \mathrm{~nm}$ (green) and $358 / 461 \mathrm{~nm}$ (blue), respectively. Photomicrographs of double/triple labeling were obtained by superimposition of green, red, and blue images. For mapping GFP-positive fibers in the dura, we captured highresolution images of the area containing positive labeling and export them to Photoshop for the creation of a photomontage. The resulting 
image was converted to grayscale, inverted, and processed in Illustrator for automatic tracing.

Vascular casting of veins and arteries of the posterior cranium. The aim of these studies was to identify blood vessels in the posterior cranium and neck muscles, particularly those entering/exiting the cranium, that are accompanied by GFP-labeled nerve fibers from C2 DRG. For this, rats that received rAAV-GFP into C2 DRG were killed (pentobarbital 150 $\mathrm{mg} / \mathrm{kg}$, i.p.) and perfused with $\mathrm{NaCl} 0.9 \%$ followed by $2-5 \mathrm{ml}$ of a lowviscosity solution of polyurethane elastomers (PU4ii, vasQtec). This solution hardens in a few hours after appropriate perfusion of alldimension blood vessels as described previously (Meyer et al., 2007). Cadaveric samples were soaked in fixative solution (PFA 4\%) for $5 \mathrm{~d}$ at $4^{\circ} \mathrm{C}$. To finalize, cadaveric dissection or tissue maceration with $7.5 \%$ $\mathrm{KOH}$ at $55^{\circ} \mathrm{C}$ was performed under a stereoscope (M80, Leica) dotted with a digital camera for imaging.

Electrophysiological identification of dura-sensitive neurons in C2-C4 dorsal horn with receptive fields in the posterior dura. For in vivo extracellular recording of central cervicovascular neurons, rats were anesthetized with urethane ( $1.5 \mathrm{~g} / \mathrm{kg}$, i.p.), intubated endotracheally, catheterized for infusion of fluids through the femoral vein, mounted on a stereotaxic frame, and monitored for physiological changes as described above. Surgical access to the upper cervical dorsal horn was performed as described before (Strassman et al., 1994; Burstein et al., 1998). Briefly, we made a midline incision of the neck skin, gently pulled neck muscles and surrounding tissue to the side, and performed a laminectomy of the $\mathrm{C} 2$ vertebra to expose the upper cervical spinal cord. For stimulation of the posterior dura overlying the cerebellum, a $3 \mathrm{~mm}^{2}$ craniotomy was performed on the left side of the vertical portion of the occipital bone after displacement of neck muscles inserted into the superior nuchal line. The exposed dura was kept moist using modified synthetic interstitial fluid, $\mathrm{pH}$ 7.2. One hour after surgery, additional immobilization of animals for recordings stability was achieved by continuous intravenous infusion of the muscle relaxant vecuronium $(1 \mathrm{mg} / \mathrm{ml})$ at a rate of $1 \mathrm{ml} / \mathrm{h}$.

Cervicovascular neurons in the $\mathrm{C} 2-\mathrm{C} 4$ dorsal horn were initially identified using electrical stimulation of the dura overlying the cerebellum $(0.5 \mathrm{~ms}$ pulse, $1 \mu \mathrm{A}, 1 \mathrm{~Hz}$ ). Once identified, their receptive fields (RFs) in the dura, neck muscles, and skin were mapped mechanically, and their spontaneous activity was monitored for $30 \mathrm{~min}$. Each neuron was characterized for its baseline responses to a series of stimuli. Quantitative stimulation of RFs on the dura and muscles were performed by indentation with a series of calibrated von Frey hairs (VFHs). Stimulation of the occipital skin included brushing with paintbrush; pressing with loose arterial clip; pinching with strong arterial clip. To induce sensitization, we applied inflammatory soup to dural RFs (IS; Bradykinin, serotonin, histamine, and PGE2) as described previously (Burstein et al., 1998). To determine whether or not a neuron got sensitized, corresponding mechanical stimuli of the dura, muscles, and skin were repeated $2 \mathrm{~h}$ after IS administration and their values were compared with those recorded before IS application. Neuronal action potentials were acquired, filtered, and amplified using a multichannel amplifier (Thomas Recording) and a Micro1401-mkII digitizer unit (CED) before sending the data to a PC for additional processing as described before (Noseda et al., 2016). Real-time waveform discrimination was also performed to detect signals originated from a single neuron and was based on template creation from spontaneous and evoked action potentials using Spike2 software (CED). At the end of each experiment, an electrolytic lesion was made to identify the spinal segment and lamina of recording sites. For this, rats were killed (150 mg/kg pentobarbital sodium, i.p.), and their cervical spinal cord removed, soaked in fixative solution (formalin 10\%) for $7 \mathrm{~d}$, cryoprotected, frozen, cut into coronal sections ( $80 \mu \mathrm{m}$ thick) using a cryostat (Leica), mounted on glass slides, counterstained, and coverslipped for image acquisition

Data analysis and statistics. Spontaneous firing rate (spikes/s), size of dural and cutaneous RFs (as drawn), and response magnitudes to mechanical stimulation of the posterior dura, neck muscle, and cutaneous RFs were determined as describe before (Burstein et al., 1998, 2010; Melo-Carrillo et al., 2017). Changes in RF sizes and response magnitude to stimulation of each of the three RFs (before and after IS) were used to identify sensitized neurons. A neuron is considered sensitized if its response magnitude to mechanical stimulation is increased by $>50 \%$.

\section{Results}

\section{Anatomical studies}

Labeling of sensory fibers innervating the posterior dura was achieved by injecting the C2 DRG with either one of the AAV vectors used in the study (Fig. 1A). In 14 of the 27 rats injected, efficient viral transduction was confirmed by identification of GFP-expressing cells in the ganglion 3 weeks after the injection. Coronal sections of C2 DRG were processed for IF to verify transduction efficiency of CGRP-positive sensory neurons. In the best three experiments, we randomly selected five sections per ganglion and estimated that $34 \%$ of cells expressed GFP, among which 9\% were immunoreactive to CGRP (Fig. 1B). Animals containing GFP-expressing neurons were carefully dissected to follow the trajectory of GFP fibers from C2 DRG to the cranium. In a cross-section ( $80 \mu \mathrm{m}$ thick) of the neck at the level of the atlas, we observed that the main nerves originating from C2 DRG (greater and lesser occipital) branch out to form large and midsize bundles of fibers traveling across and on the surface of neck muscles such as acromiotrapezius, splenius, and semispinalis capitis before entering the skull. Bundles of GFP fibers from C2 DRG were mostly observed traveling along and around blood vessels. Single GFP fibers were also found in muscle fascia and penetrating muscle fascicles (Fig. 1C). After their tortuous path across neck muscles, many GFP fibers entered the cranium through mainly five points: (1) a mid-size canal formed between the lateral aspect of the occipital bone and the periotic capsule, where mid-size veins and GFP fibers access the posterior dura from the side; (2) emissary canals in the lateral aspect of the occipital condyle, where small size veins and GFP fibers reach the posterior dura from the side; (3) hypoglossal canal in the ventrolateral aspect of the occipital condyle, where GFP fibers innervate the ventral and lateral part of the cerebellar dura; (4) foramen magnum, where fibers originating in C2 DRG densely innervate the cervical spinal dura and travel rostrally to reach the most caudal part of the dura overlying the cerebellum as well as the floor of the posterior cranial fossa; and (5) jugular foramen in the caudal base of the skull between the tympanic bulla and lateral aspect of the occipital bone, where GFP fibers innervate ventral areas of the cerebellar dura (Fig. $1 D, E$ ). These entry points into the cranium were identified using vascular casting of blood vessels with synthetic polyurethane resin, as described above.

Although GFP fibers enter the cranium along with blood vessels, they bifurcate and spread extensively within the intracranial dura. These dural GFP-labeled axons were immunoreactive to CGRP, suggesting that they are nociceptive in origin (Fig. 2A). Dural innervation originating in C2 DRG was identified exclusively in the posterior dura (i.e., from the caudal border of the transverse sinus to the spinomedullary junction) and cervical spinal dura (i.e., from the spinomedullary junction to $\mathrm{C} 2-\mathrm{C} 3$ border; Fig. $2 B, C)$. Whole-mount dura was used to map the distribution of C2 DRG innervation in the posterior and spinal dura. Multiple adjacent images were acquired and processed for photomontage to reconstruct the trajectory of GFP-labeled fibers as shown in Figure 2D. GFP-labeled axons were neither found in areas of the dura anterior to the caudal border of the transverse sinus nor in the tentorial dura.

In a different set of experiments, we applied the retrograde tracer FG on a discrete area of the posterior dura to determine relative amount and type of C2 DRG neurons innervating this area (Fig. 3A). Retrogradely labeled cells were observed in 8 of 13 
A

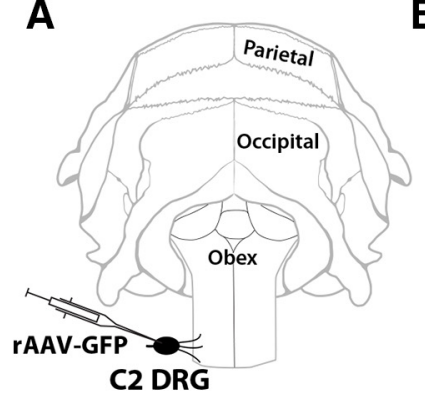

B

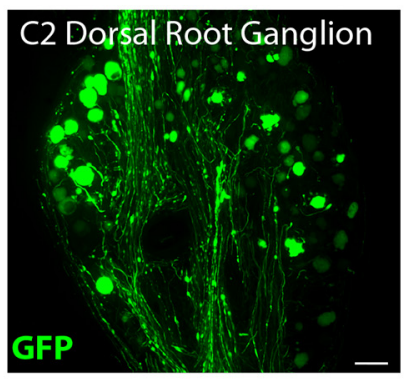

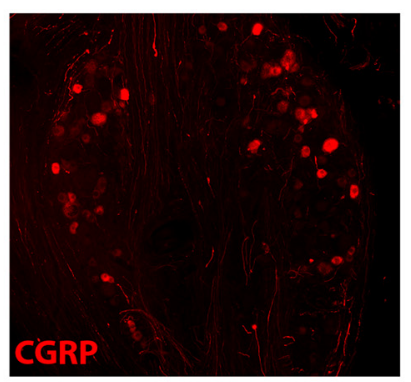

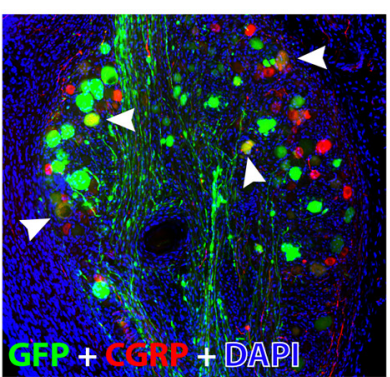

\section{Neck muscles cross-section}
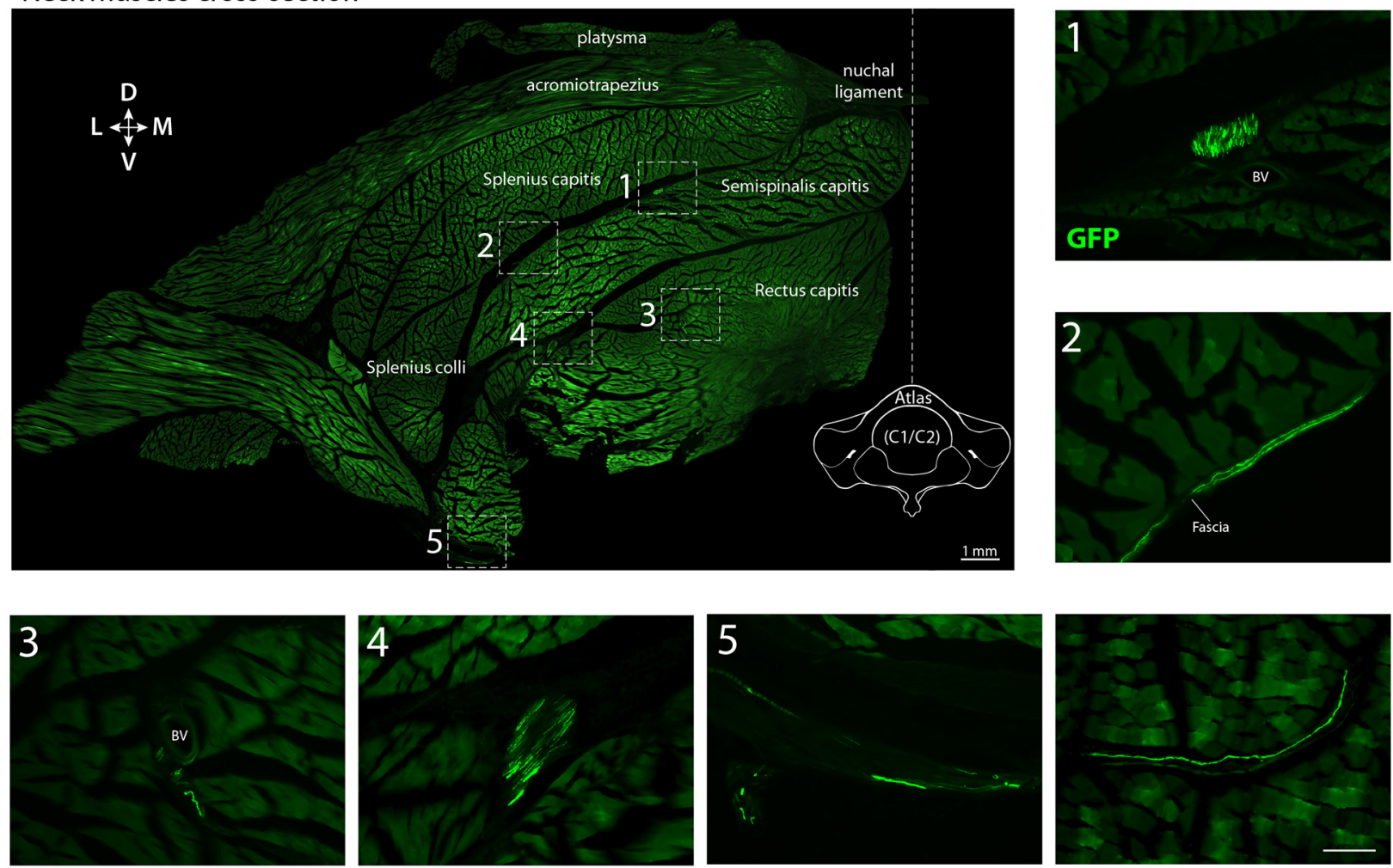

D

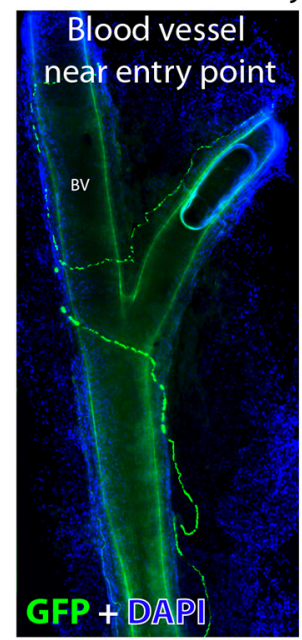

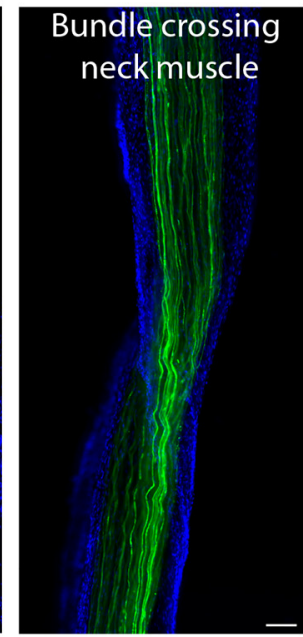

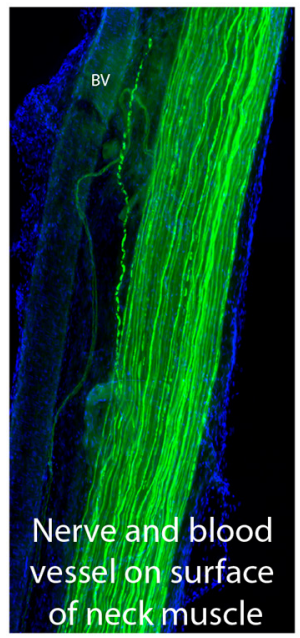

E Skull entry points along blood vessels (vascular casting in blue)

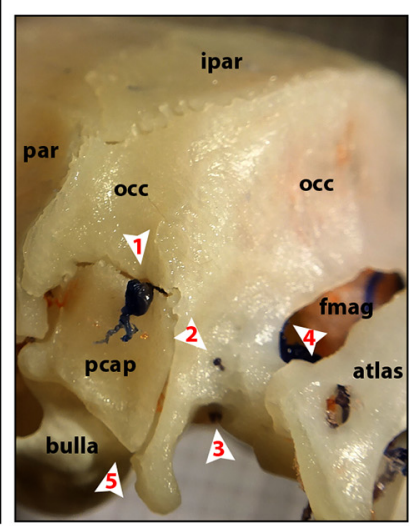

Figure 1. Anterograde tracing of $(2 D R G$ peripheral axons to the posterior dura (extracranial component). $A$, Illustration of the rat's skull view from behind showing intra-ganglionar injection of rAAV-GFP viral vector into C2 DRG. B, Transversal view of a C2 DRG section showing GFP expression in successfully transduced cells (green, left), some of which were also immunoreactive to CGRP (red, middle). Superimposition of these images and DAPI (blue) is displayed at the right with white arrowheads indicating double-labeled cells (yellow). C, (ross-section of the whole neck at the level of C1 vertebra showing the distribution and trajectories of GFP-labeled nerves and fibers traveling along blood vessels (BV), fascia, and muscle from (2 DRG to the cranium. The image shows the left dorsolateral quadrant of the neck and was created by stitching 268 high-resolution images into a single composite. Numbers and frames indicate the areas where the images displayed (Figure legend continues.) 
A Intracranial trajectories of C2 DRG nerve fibers
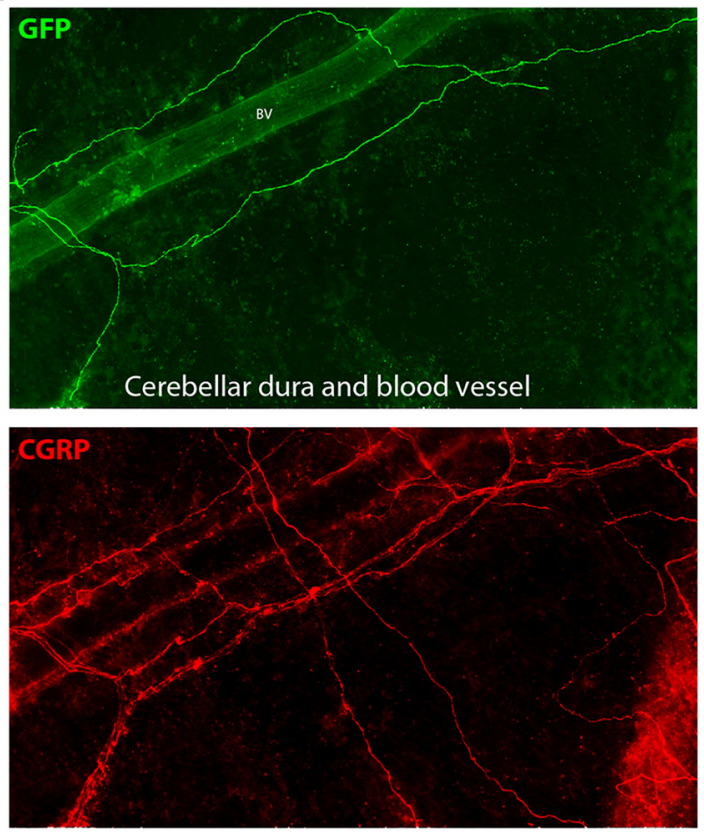

DAPD
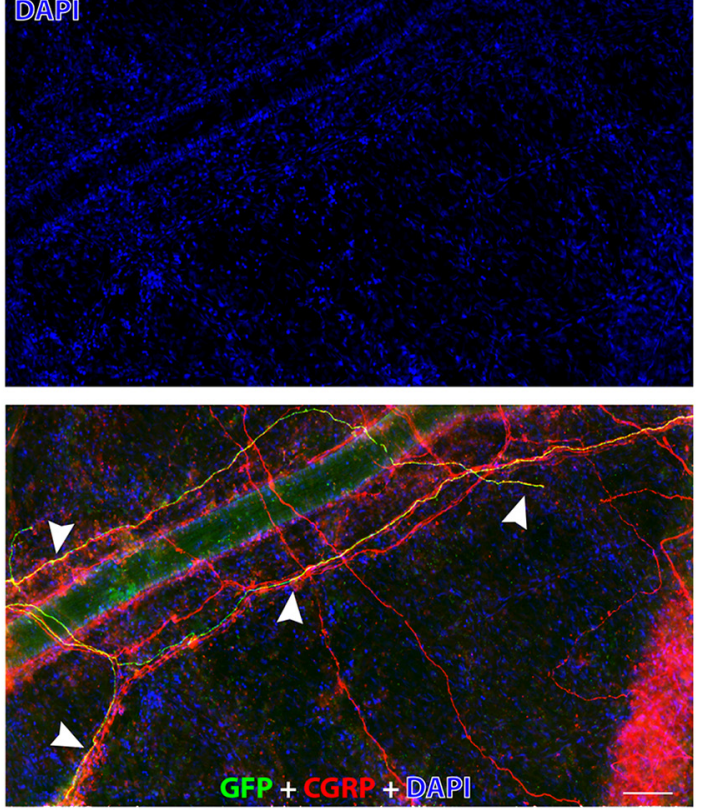

B
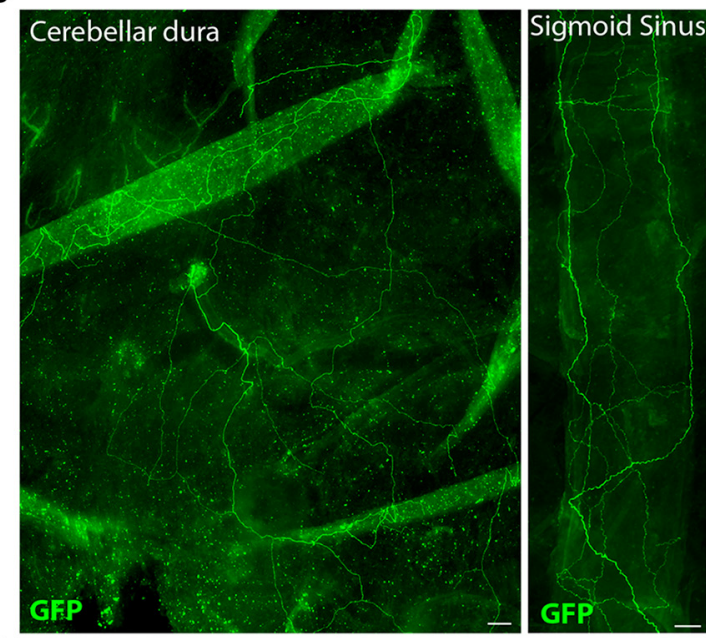

C Cervical Spinal Dura
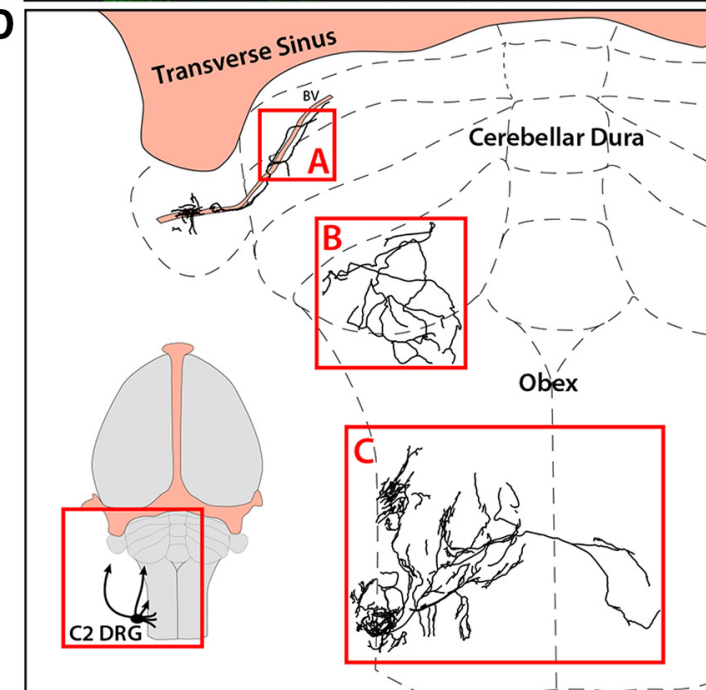

Figure 2. Anterograde tracing of C 2 DRG peripheral axons in the posterior dura (intracranial component). $A$, Flat mount of the dura overlying the cerebellum showing GFP-labeled axons from C2 DRG spreading within the dura immediately after entering the cranium. These GFP-labeled dural axons were immunoreactive to (GRP (red) as evidenced in the superimposition of images at the bottom, where white arrowheads indicate double labeling of these axons (yellow) in the DAPI (blue) counterstained dura. $\boldsymbol{B}$, Representative examples of GFP-labeled axons spreading extensively within the posterior dura overlying the cerebellum (left), large intra-cranial blood vessels (right), and ( $\boldsymbol{C}$ ) the dura covering the upper cervical segments of the spinal cord. $\boldsymbol{D}$, Reconstruction of the GFP-labeled axons shown in $\boldsymbol{A}-\boldsymbol{C}$. Inset, Illustration of the rat brain showing the region of interest. Scale bars, $100 \mu \mathrm{m}$.

rats receiving FG and were mostly located in the anterior half of the $\mathrm{C} 2$ ganglion (Fig. 3B). In successful experiments, the total number of FG-positive neurons per ganglion, found in $\sim 40$ cross-sections of $20 \mu \mathrm{m}$ thick, was $194.7 \pm 24.1$ (mean $\pm \mathrm{SD}$ ),

$\leftarrow$

(Figure legend continued.) at the right and bottom were taken. The only not-numbered image was taken from another cross-section of the neck in the same animal. $\boldsymbol{D}$, Cervical nerves and bundles of fibers expressing GFP wereobserved crossingneckmuscles, travelingalong bloodvessels and fascia beforeentering the cranium in the occipital region through $(\boldsymbol{E})$ a canal between the occipital bone (occ) and the periotic capsule (pcap) (1),emissarycanalsneartheoccipital condyle(2), the hypoglossal canal (3), foramen magnum (fmag) (4), and jugular foramen (5). Interparietal bone (ipar), parietal bone (par). Scale bars, $100 \mu \mathrm{m}$. among which $19.5 \%$ were classified as large $(\mathrm{L} ;>35 \mu \mathrm{m})$ and $80.5 \%$ as small $(\mathrm{S} ;<35 \mu \mathrm{m})$ based on cell body diameter. The three C2 ganglia presenting the largest number of FG-labeled cells $(218,213$, and 208 cells per ganglion) were selected and additionally processed for IF to identify their neurochemical content. We found that $57.4 \%$ of all FG retrogradely-labeled neurons were immunoreactive to CGRP (58.3\% for L neurons; $57.1 \%$ for S) and $49.2 \%$ to TRPV1 $(9.1 \% \mathrm{~L} ; 57.4 \% \mathrm{~S})$. We also found that only $4.8 \%(14.3 \% \mathrm{~L} ; 2.9 \% \mathrm{~S})$ of all FG-positive neurons contained IB4 (Fig. 3C). For C3 DRG, the total number of FGpositive neurons per ganglion, found in $\sim 40$ cross-sections of 20 
$\mu \mathrm{m}$ thick, was $223.6 \pm 28.2$ (mean $\pm \mathrm{SD}$; $n=3$ ), among which $18.2 \%$ had large and $81.8 \%$ small cell bodies (data not shown). When FG was applied in restricted areas of the dura underneath the occipital bone, no labeled cells were found in C4 or in the TG. In contrast, when FG was placed on the anterior and dorsal portion of the posterior dura, retrograde labeling of TG cells was detected. In fact, the closer to the transverse sinus the FG was placed, the larger the number of neurons we found labeled in the TG.

\section{Electrophysiological study}

We performed extracellular single-unit recordings in the upper cervical spinal cord of 14 rats. A total of 21 neurons were successfully isolated. Among them, we identified 12 neurons with distinct responses to (1) electrical and (2) mechanical stimulation of the posterior dura as well as mechanical stimulation of superficial and deep neck muscles and the occipital skin (Fig. 4). Based on electrolytic lesions made at the end of each experiment, neurons were distributed across laminae I-V, spanning $\sim 2.5 \mathrm{~mm}$ from $\mathrm{C} 2$ to $\mathrm{C} 4$ segments of the cervical spinal cord (Fig. 5), and based on their responses to innocuous and noxious mechanical stimulation of the skin, they were all classified as Wide Dynamic Range (WDR) (Fig. 4B).

All intracranial RFs were ipsilateral, located in the dura overlying the posterior aspect of the cerebellum (vertical orientation in the rat; Fig. $6 A$ ). In the naive state, indentation of each of the 12 dural RFs with $4 \mathrm{~g}$ (VFH) induced sustained and brief neuronal responses (Fig. 6B). Two hours after local application of IS to the dural RFs, indentation with the same mechanical force triggered responses that were at least $50 \%$ larger in magnitude than those recorded in the naive state (Fig. 6C). Such enhanced responses (suggestive of sensitization) were recorded in 7/12 $(58 \%)$ neurons, and showed an increase from $6.7 \pm 2.7$ to $11.4 \pm 4.1$ (mean \pm SEM) spikes/s (see Fig. 9A). In five cases, dural RFs expanded beyond their original size (Fig. 6A).

Our ability to map the muscle RFs of the posterior dura-sensitive neurons was limited by the fact that many of the axons that carry sensory information from the posterior dura to the dorsal horn pass through and bifurcated in the muscles themselves. We intentionally avoided excessive or unnecessary manipulation of neck muscles during the experiments to keep anatomical integrity and minimize
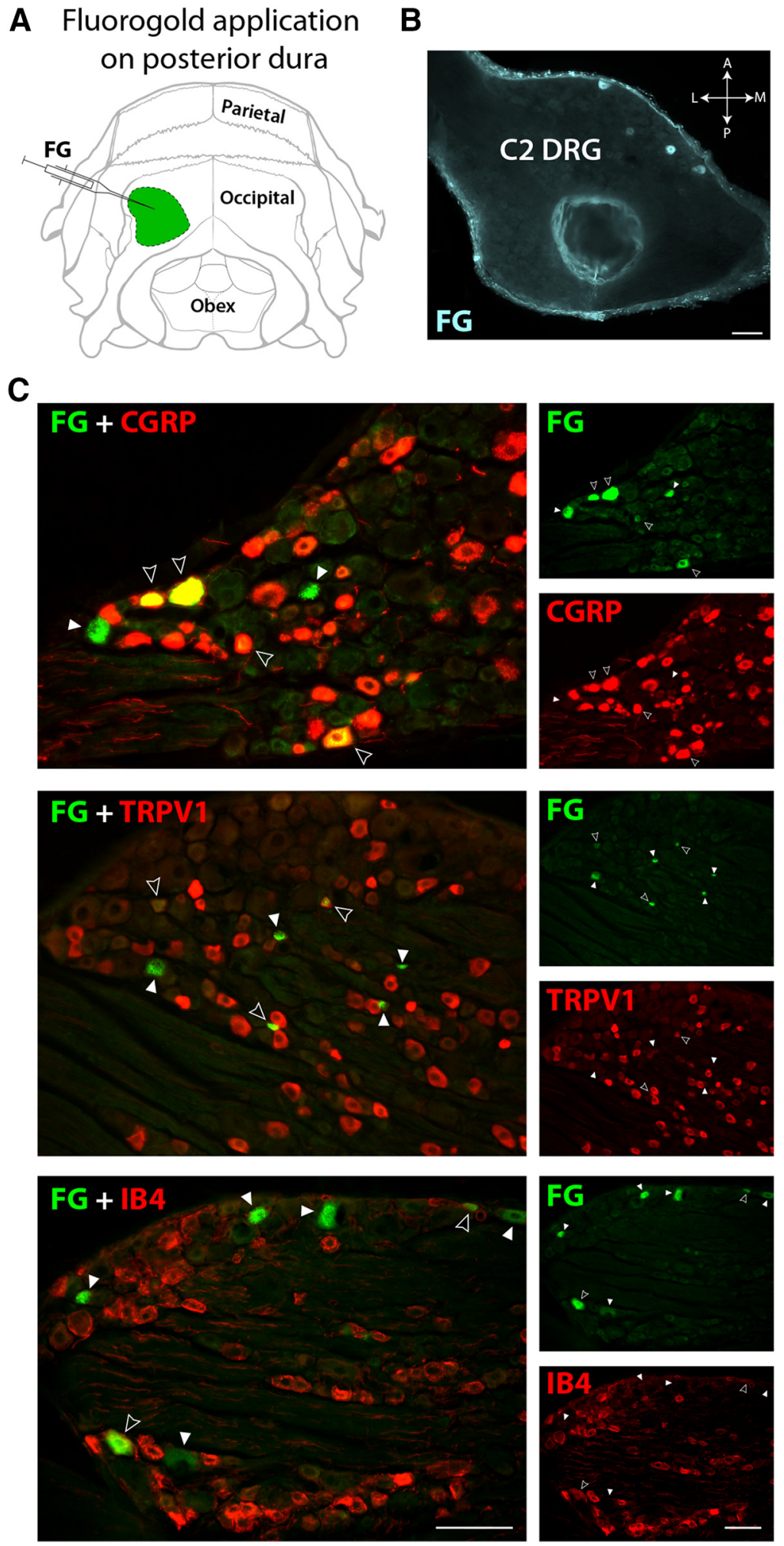

Figure 3. Retrograde labeling in C 2 DRG from the posterior dura. $A$, Illustration of the rat's skull view from behind showing the area of $\mathrm{FG}$ application (green) on the posterior dura. $\boldsymbol{B}$, Transversal view of a $\mathrm{C} 2 \mathrm{DRG}$ section showing retrogradely-labeled neurons filled with FG near the anterior edge of the left ganglion. C, A proportion of FG-labeled neurons (green) in C2 DRG was also immunoreactive to CGRP, TRPV1, or IB4 (red). Images in the left column were created by superimposition of the images in the right column. Filled arrowheads point to FG-positive cells. Open arrowheads indicate double-labeled cells with FG and with each of the three markers of sensory neurons used (yellow). Scale bars, $100 \mu \mathrm{m}$. 
A Dural, muscle and cutaneous receptive fields
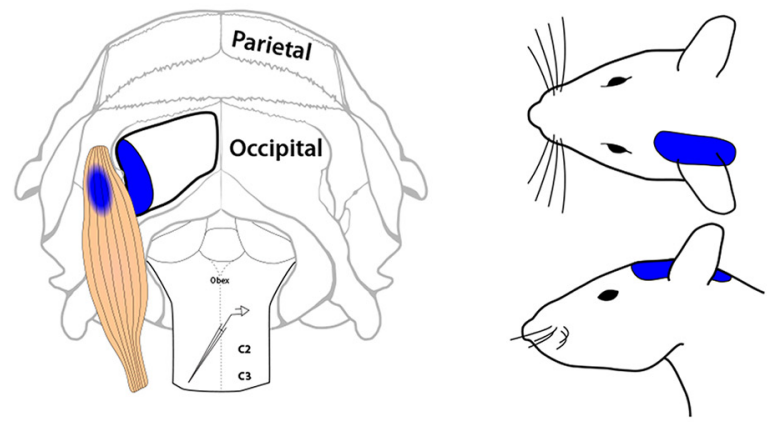

B Identification of dura-sensitive neurons
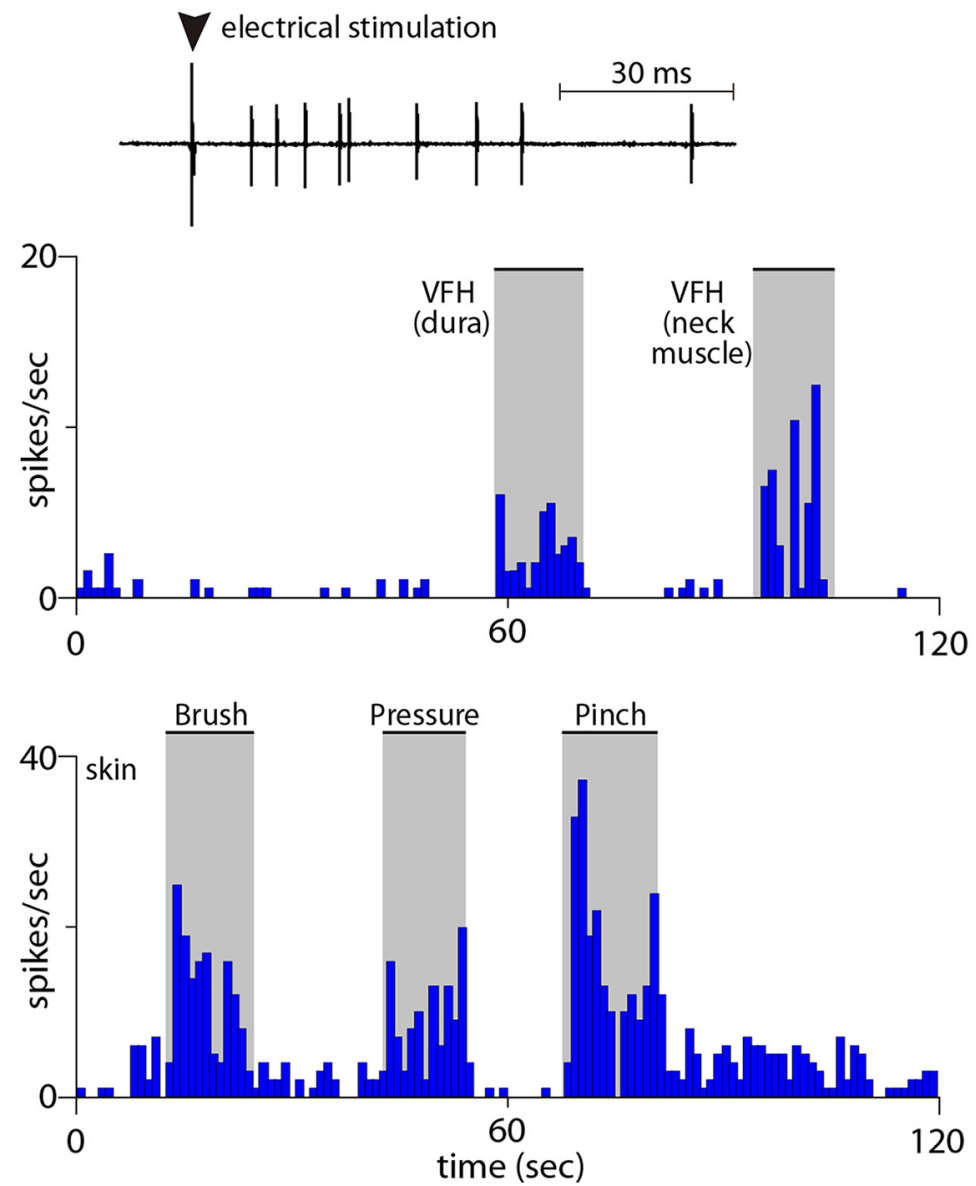

Figure 4. Electrophysiological characterization of posterior dura-sensitive neurons in C2-C4 dorsal horn. $\boldsymbol{A}$, Illustration of the rat's skull, exposed posterior dura, neck muscles, and skin showing the mapping of all RFs obtained from a single dura-sensitive neuron at baseline. $\boldsymbol{B}$, Identification of $\mathrm{C} 2-\mathrm{C} 4$ neurons responding to electrical and mechanical stimulation of the posterior dura, neck muscle, and skin.

the damage to these axons. Accordingly, we were unable to map muscle RFs reliably, because it required invasive manipulation of muscles to measure expansion of their RFs accurately. Although our impression was that expansion of muscle RFs occurred in some experiments, we limited our assessment by only identifying the most sensitive area in superficial (acromiotrapezius) and/or deep (semispinalis capitis and rectus capitis) muscles without further assessment of expansion. Figure $7 \mathrm{~A}$ illustrates the most sensitive sites to mechanical stimulation in each of these muscle groups. In the naive state, indentation of each of the 12 muscle RFs with $4 \mathrm{~g}$ (VFH) induced sustained and brief neuronal re- sponses (Fig. 7B). Two hours after local application of IS to the dural RFs, indentation of the muscle RFs with the same mechanical force triggered responses that were at least $50 \%$ larger in magnitude than those recorded in the naive state (Fig. 7C). Such enhanced responses (suggestive of sensitization) were recorded in 6/12 (50\%) neurons, and increased from $4.3 \pm$ 1.9 to $9.1 \pm 3.3$ (mean \pm SEM) spikes/s (Fig. 9B).

Unlike the mostly periorbital and facial cutaneous RFs of neurons in the spinal trigeminal nucleus whose dural RFs extend over the transverse or superior sagittal sinuses, the cutaneous RFs of the posterior dura-sensitive neurons extended over the ear, the lateral portion of the occipital region and neck (Fig. $8 A$ ). In the naive state, mechanical stimulation of these cutaneous RFs induced typical responses to brush, pressure, and pinch (Fig. 8B, left columns). Two hours after local application of IS to the dural RFs, responses to brush, pressure, and pinch increased $>50 \%$ in five $(7.1 \pm 1.1$ to $16.6 \pm 2.8$ spikes/s), three $(10.1 \pm 5.2$ to $21.5 \pm 8$ spikes/s), and three (11.6 \pm 4.4 to $24.7 \pm 8.3$ spikes/s) cases, respectively (Fig. 8B, right columns; Fig. 9C). As in the dura, cutaneous RFs expanded in five cases after application of IS on the posterior dura (Fig. 8A).

\section{Discussion}

Using sophisticated anatomical labeling and single-unit recording techniques, we show (1) that axons of sensory neurons in C2 and C3 DRGs innervate the dura overlying the cerebellum and the posterior fossa; (2) that they enter the cranium through bony canals in the occipital bone (occipital-periotic, emissary, hypoglossal), and large foramens (magnum, jugular); (3) that they reach the occipital bone after traversing the different layers of the suboccipital muscles; (4) that nearly 50\% of them originate in neurons that contain CGRP, TRPV1, but not IB4; (5) that dorsal horn neurons that receive nociceptive information from the posterior/occipital dura are located in $\mathrm{C} 2-\mathrm{C} 4$ spinal cord segments and that their cutaneous and muscle RFs are centered around the ears, occipital and upper neck skin, and superficial and deep neck muscles, and (6) that administration of inflammatory soup to their intracranial dural RF, sensitizes a subpopulation of them to the extent that they become hyper-responsive to simulation of the occipital skin and neck muscles. To the best of our knowledge, this study is first to identify the course that axons of DRG cells take from outside to inside the cranium. Clinically, the findings raise the possibility that occipital headaches may differ from periorbital, frontal, and temporal headaches by virtue of the involved tissues (dura overlying the cerebellum vs dura 


\section{Recording sites in C2-4}
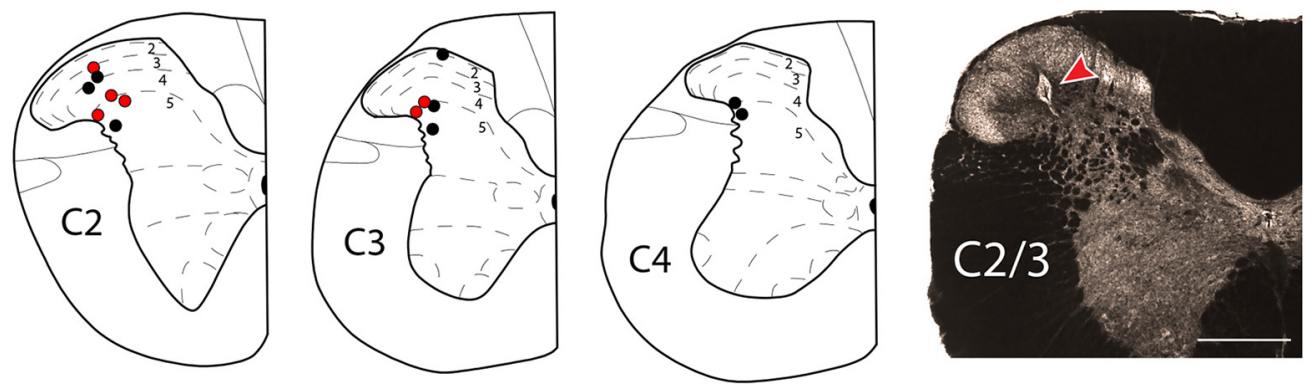

Figure 5. Schematic representation of 2 to 44 spinal cord segments showing the recording sites marked by electrolytic lesions made at the end of each experiment. Red dots represent recording sites where neurons displaying sensitized responses were found. An example of these lesions in C 2 spinal cord segment is shown in the dark-field image at the right. Scale bar, $500 \mu \mathrm{m}$.

overlying sensory cortices), the origin of the neurons that mediate these headaches (C2-C3 DRGs vs TG), the course that their axons take (extracranial to intracranial vs intracranial only), and the functional pathway they establish for mediating muscle tenderness that develop after (rather than before) the onset of headache. Therapeutically, the findings lend rationale for the common practice of attempting to alleviate migraine by targeting the greater and lesser occipital nerves with anesthetics (e.g., lidocaine), anti-inflammatory (e.g., steroids), or preventative (e.g., onabotulinumtoxinA, occipital nerve stimulator) drugs or devices (Aurora et al., 2010; Diener et al., 2010; Chen et al., 2015; Yang et al., 2016; Tang et al., 2017; Zhang et al., 2018). Scientifically, it is reasonable to hypothesize that occipital nerve manipulation may be more beneficial for alleviating occipital than non-occipital headaches and that occipital migraines may be associated more closely (than non-occipital migraines) with cerebellar-mediated symptoms and abnormalities. The rationale for suggesting that manipulation of the greater or lesser occipital nerve may be more beneficial for the treatment of occipital headache is based on two lines of evidence. The first is that occipital nerve decompression surgeries appear to alleviate occipital but not frontal or periorbital headache (Blake et al., 2018), and the second is the long line of evidence for repeated failure of occipital nerve stimulation to decrease migraine (frequency, duration, intensity) compared with sham stimulation (Dilli et al., 2015).

The earliest identification of pain-sensitive fibers in the posterior fossa is found in two landmark studies (Penfield and McNaughton, 1940; Ray and Wolff, 1940) in which stimulation of the dura within the posterior fossa (i.e., near the foramen magnum, inferior wall of the transverse sinus, sigmoid sinus, segments of the occipital sinus, and vertebral and posterior inferior cerebellar arteries) induced in awake patients the perception of pain in occipital areas of the head (between the ears). In the years that followed, only two anatomical studies attempted to delineate the innervation origin of the posterior fossa. The first, conducted in human fetuses, showed that the dura mater covering the lateral and posterior walls of the posterior fossa is supplied by branches of neurons in the $\mathrm{C} 1$ and $\mathrm{C} 2 \mathrm{DRG}$ and that the axons enter the cranium through the jugular and hypoglossal foramens (Kimmel, 1961). The second, conducted in cats and used retrograde tracing technique, showed that the sensory innervation of the posterior fossa can be found in C1, C2, and C3 DRGs as well as the trigeminal ganglion (Keller et al., 1985). Using more advanced techniques, the current study expands on these earlier descriptions, to the extent that it allows us to identify additional courses that axons of C2-C3 DRG cells take on their way to the posterior dura, as well as map more precisely their distribution in the in- tracranial dura itself. Therapeutically, the actual identification of occipital nerve axons that issue branches that enter the skull behind the ear (through a mid-size canal formed between the lateral aspect of the occipital bone and the periotic capsule), and lateral to the midline (through emissary canals in the occipital bone) is important because it provides a strong rationale for the common clinical practice of blocking the greater and lesser occipital nerves in attempt to treat ongoing migraine, both acutely and prophylactically. Scientifically, the identification of extracranial origin of innervation of the intracranial dura adds a novel view through which one can conceptualize possible interactions between events that occur outside and inside the cranium. Until now, it was thought that sensory/nociceptive fibers that cross the bones of the calvaria originate in the intracranial dura and exit the skull through the sutures (Kosaras et al., 2009; Schueler et al., 2013, 2014). The current study shows that at least some of the sensory/ nociceptive axons that innervate the intracranial dura of the posterior fossa originate outside the cranium.

Migraines are not classified according to the location of the headache and consequently, occipital migraine (migraine in which the headache is restricted to the occipital region only) is not a recognized term. In the absence of such terminology, one cannot find detailed description in the literature about patients whose migraine headaches affect the back of the head only. In contrast, some information exists about migraine attacks in which the headache begins as mild, bilateral, occipital headache that over time radiates frontally to involve the temple and periorbital regions. In either case, it may be reasonable to speculate that the initiation of the headache coincides with early activation of pain fibers in the occipital region of the head. To this extent, much attention had been given to the possibility that upper neck and spine pathophysiology involving muscles, nerves and bone structures may be at the origin of most occipital headaches; those that progress into migraine and those that do not (Sjaastad and Fredriksen, 2000; Headache Classification Committee of the International Headache Society, 2013). The current study raises an additional scenario for the origin of migraine headaches in which the pain is distinctly restricted to or begins in the occipital region. By showing a rich innervation of meningeal nociceptors in the dura overlying the cerebellum, the findings call attention to the possibility that, such as in the case of hyperexcitable cerebral cortex, hyperexcitable cerebellar cortex may be sufficient to provide a triggering stimulus.

The cerebellum is involved in the regulation of neurological functions such as motor control, learning, and memory (Schmahmann, 1991, 1996, 2004; Gilman, 2000; Ito, 2006; Stoodley and Schmahmann, 2009), and in the context of this study, 
A
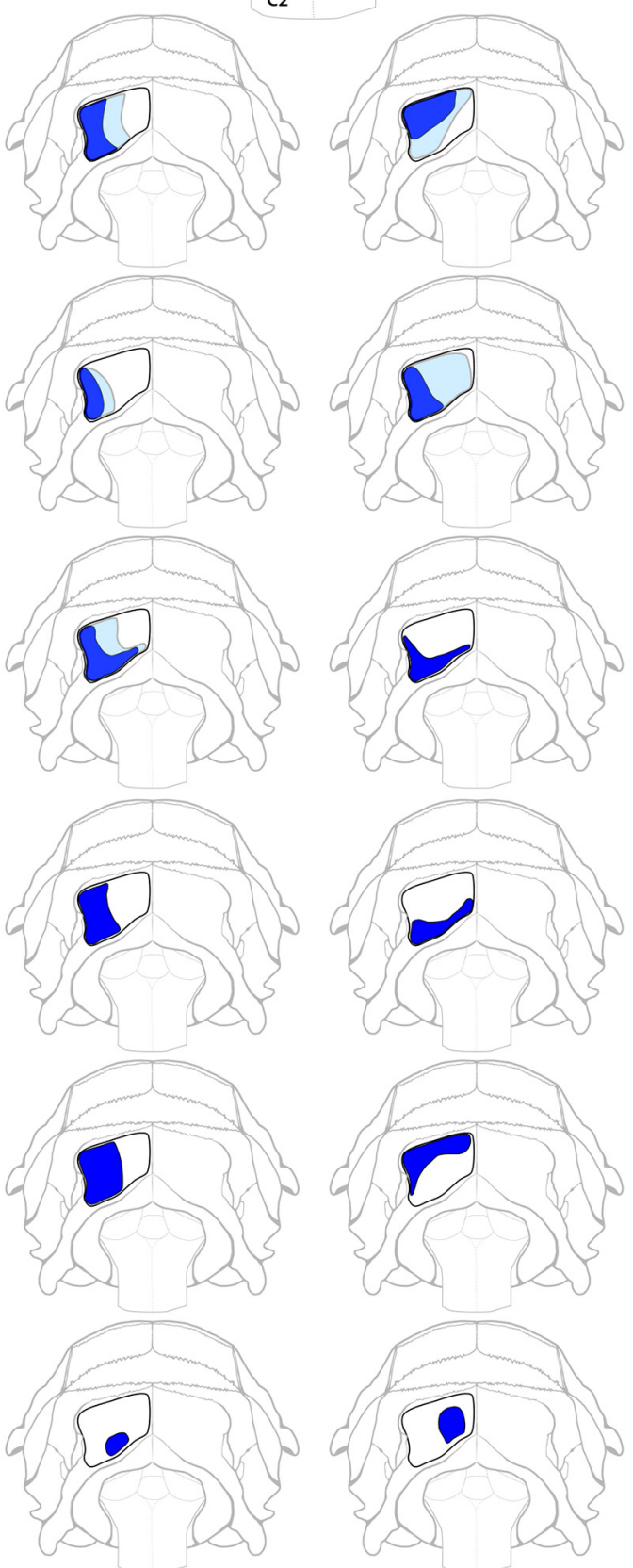

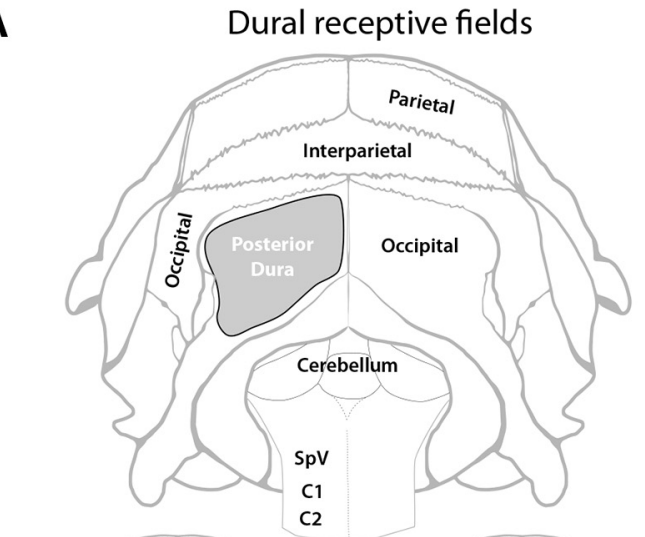

\section{B Mechanical stimulation of C Mechanical stimulation of posterior dura before IS posterior dura $2 \mathrm{~h}$ after IS}
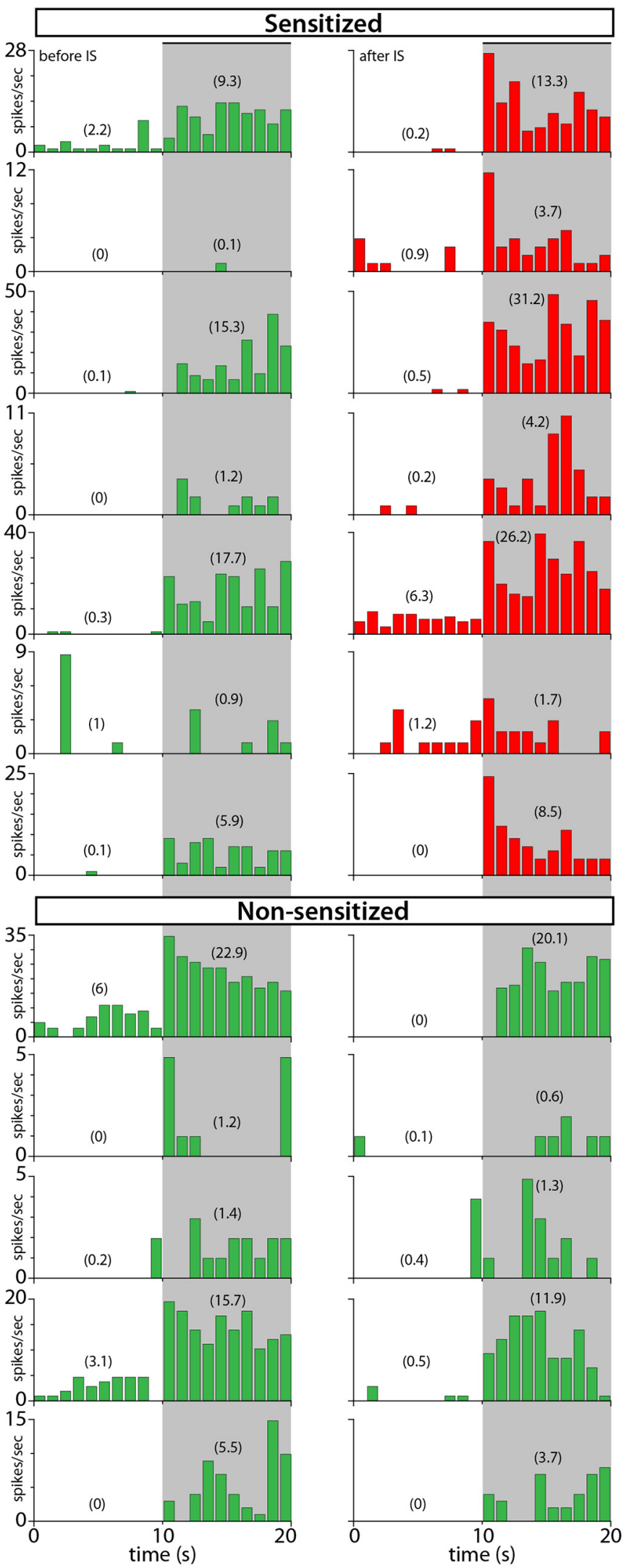

Figure 6. RFs and neuronal responses to mechanical stimulation of the posterior dura. $A$, Illustration of the rat's skull showing the area of exposition of the posterior dura (gray) and dural RFs of C2-C4 spinal cord dura-sensitive neurons measured during mechanical stimulation with VFH at baseline (dark blue) and $2 \mathrm{~h}$ after application of IS (light blue). B, C, Responses of individual neurons to mechanical stimulation of the posterior dura before (B) and after IS (C). Neurons were classified as sensitized (red) if their response magnitude increased by at least $50 \%$ after IS. Numbers in parenthesis represent firing rate in mean spikes/s during baseline (10 s) and stimulation (10 s). Shaded areas indicate the period of mechanical stimulation. 
A Neck muscle receptive fields
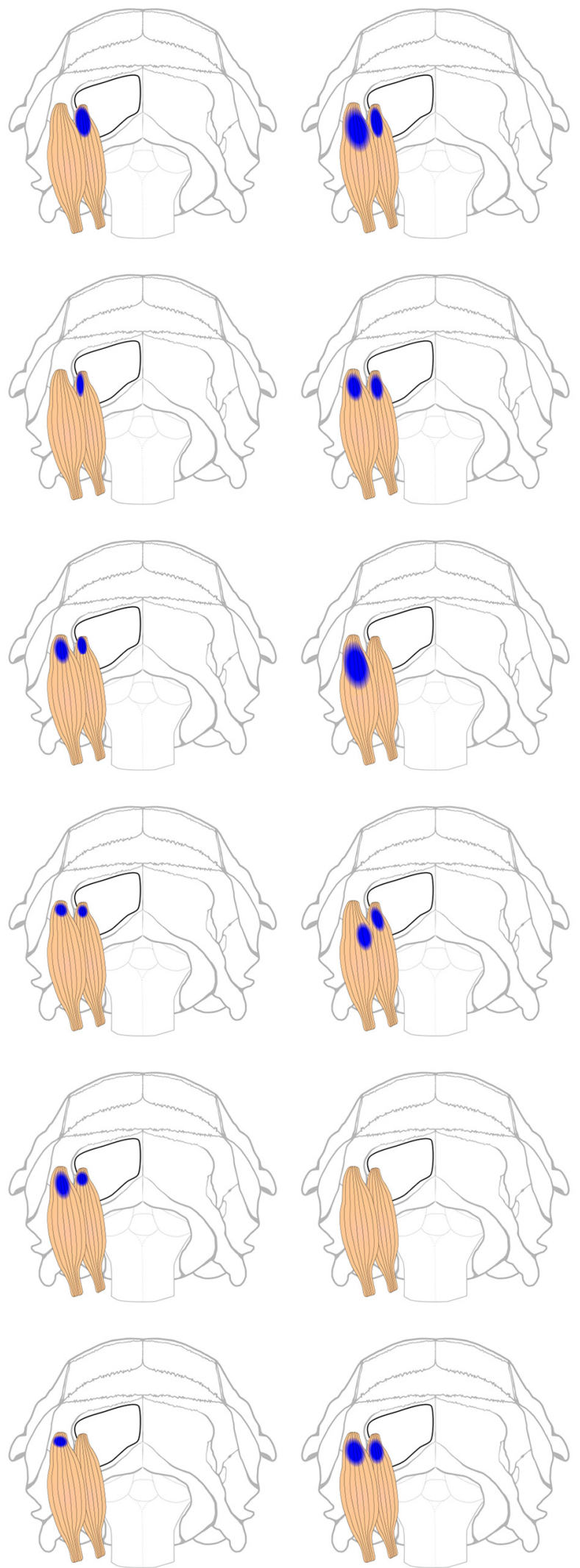

B Mechanical stimulation of

C Mechanical stimulation of neck muscle $2 \mathrm{~h}$ after IS
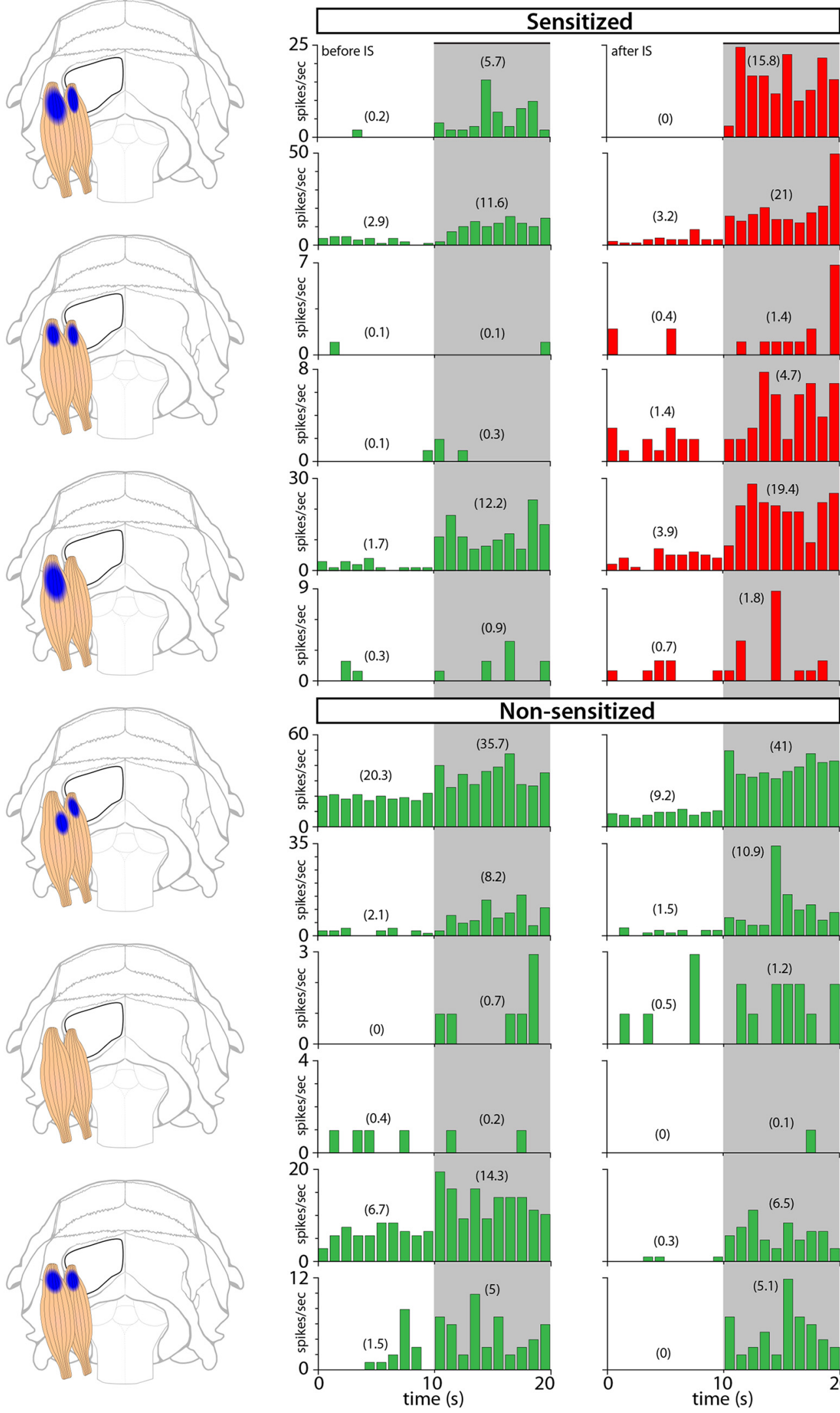
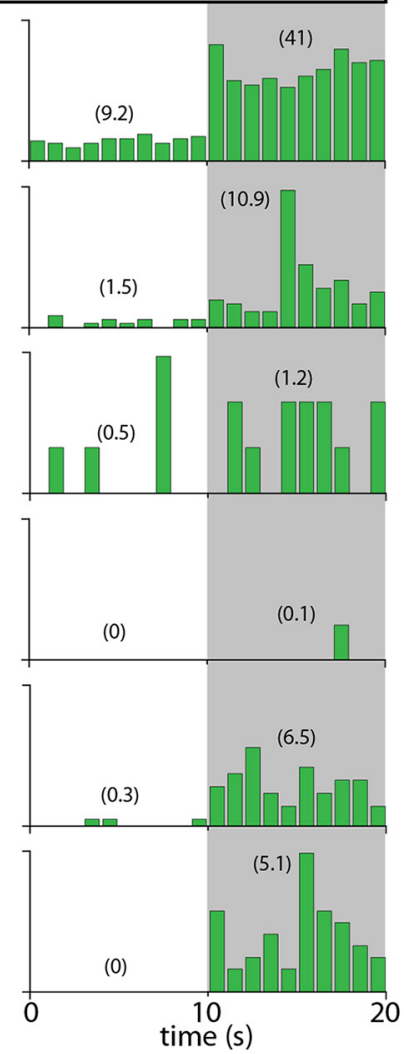

Figure 7. RFs and neuronal responses to mechanical stimulation of neck muscles. $A$, Illustration of superficial and deep group of neck muscles showing the most sensitive area (blue) to mechanical stimulation with VFH. $\boldsymbol{B}, \boldsymbol{C}$, Responses of individual neurons to mechanical stimulation of muscle RFs before ( $\boldsymbol{B}$ ) and after IS (C). Neurons were classified as sensitized (red) if their response magnitude increased by at least $50 \%$ after IS. Numbers in parenthesis represent firing rate in mean spikes/s during baseline (10 s) and stimulation (10 s). Shaded areas indicate the period of mechanical stimulation. 
A Cutaneous receptive fields
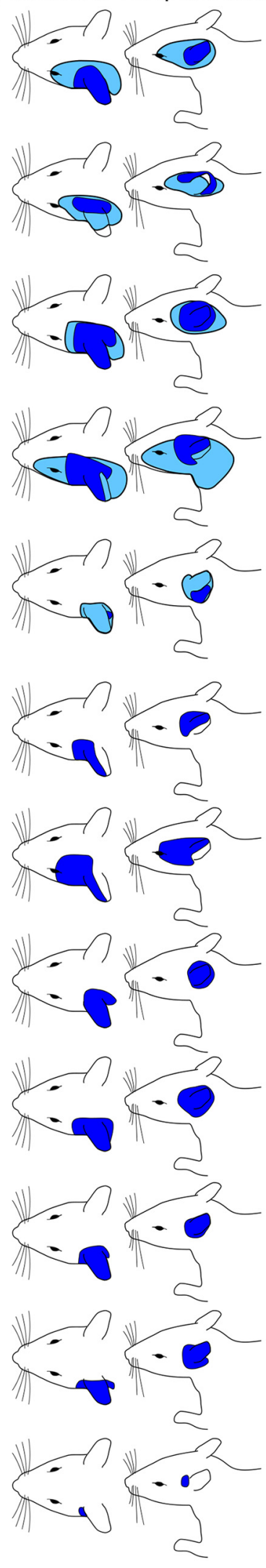

B

Mechanical stimulation of skin before and $2 \mathrm{~h}$ after IS
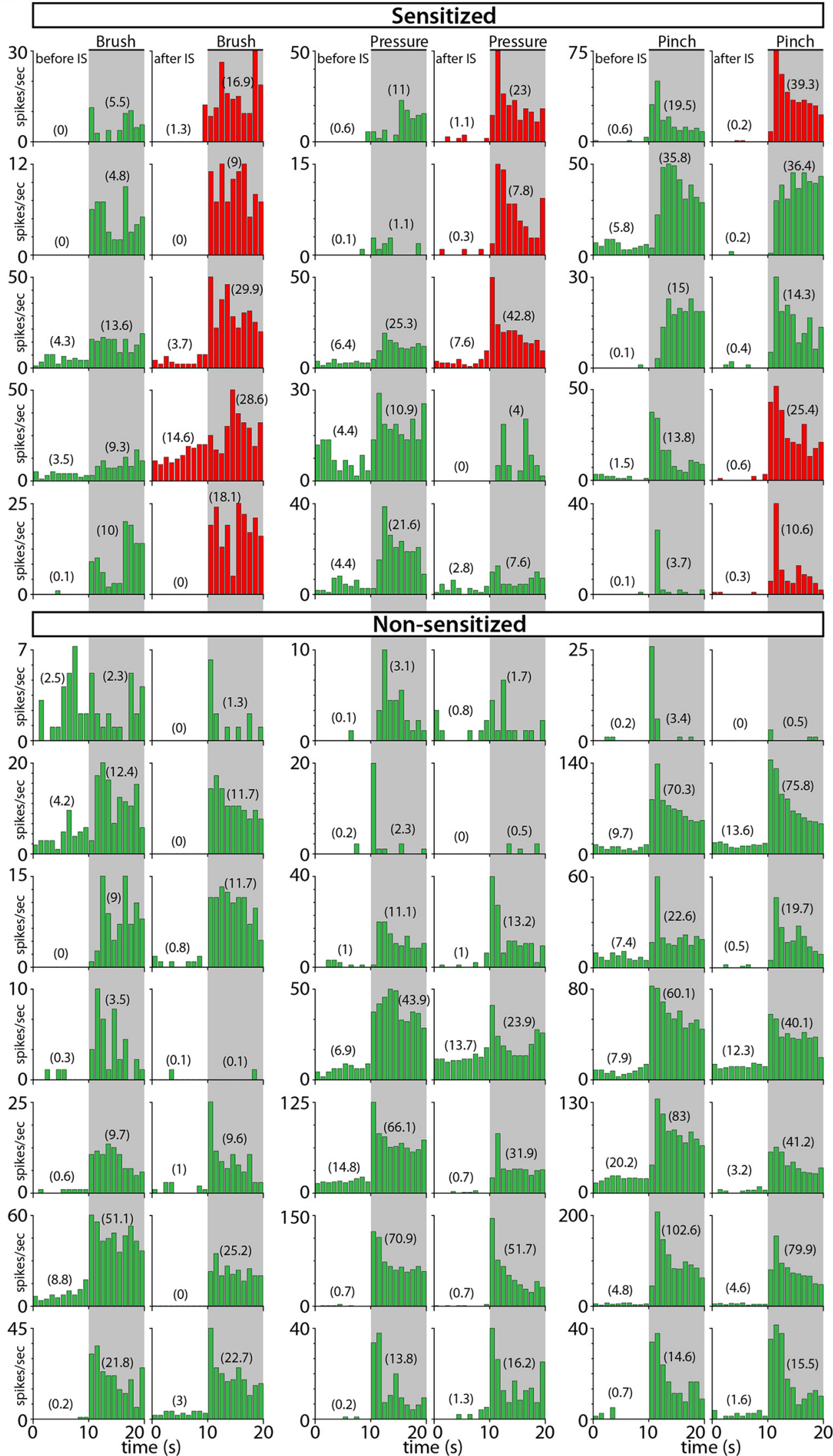

Figure 8. RFs and neuronal responses to innocuous and noxious mechanical stimulation of the skin. $A$, Illustration of the rat's head and neck showing the cutaneous RFs of $C 2-C 4$ spinal cord dura-sensitive neurons measured during mechanical stimulation at baseline (dark blue) and $2 \mathrm{~h}$ after application of IS (light blue). $\boldsymbol{B}$, Responses of individual neurons to mechanical stimulation (brush, pressure, and pinch) of the skin before (left columns) and after IS (right columns). Neurons were classified as sensitized (red) if their response magnitude increased by at least $50 \%$ after IS. Numbers in parenthesis represent firing rate in mean spikes/s during baseline (10 s) and stimulation (10 s). Shaded areas indicate the period of mechanical stimulation. 


\section{A Sensitized responses to mechanical stimulation of the posterior dura}

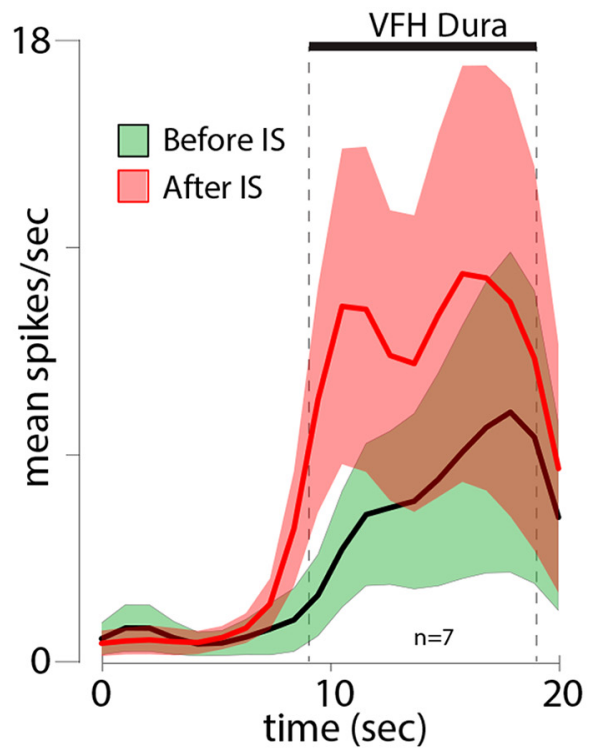

\section{B Sensitized responses to mechanical stimulation of neck muscles}

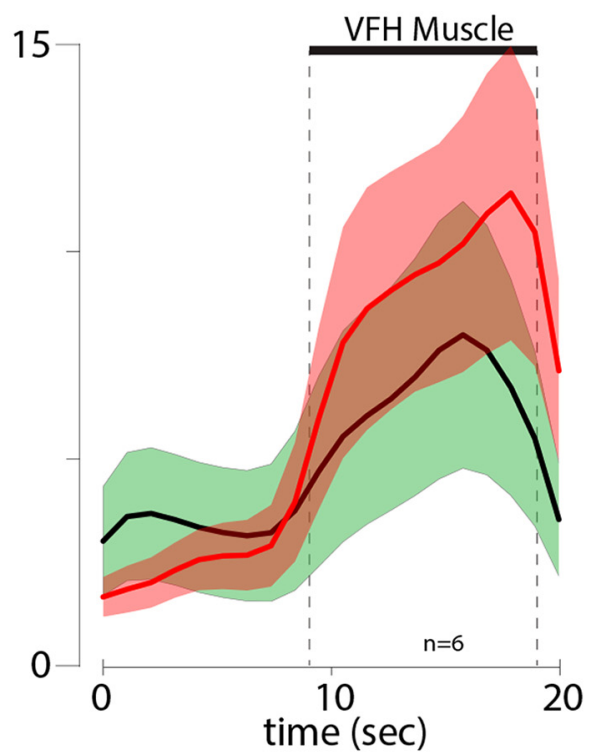

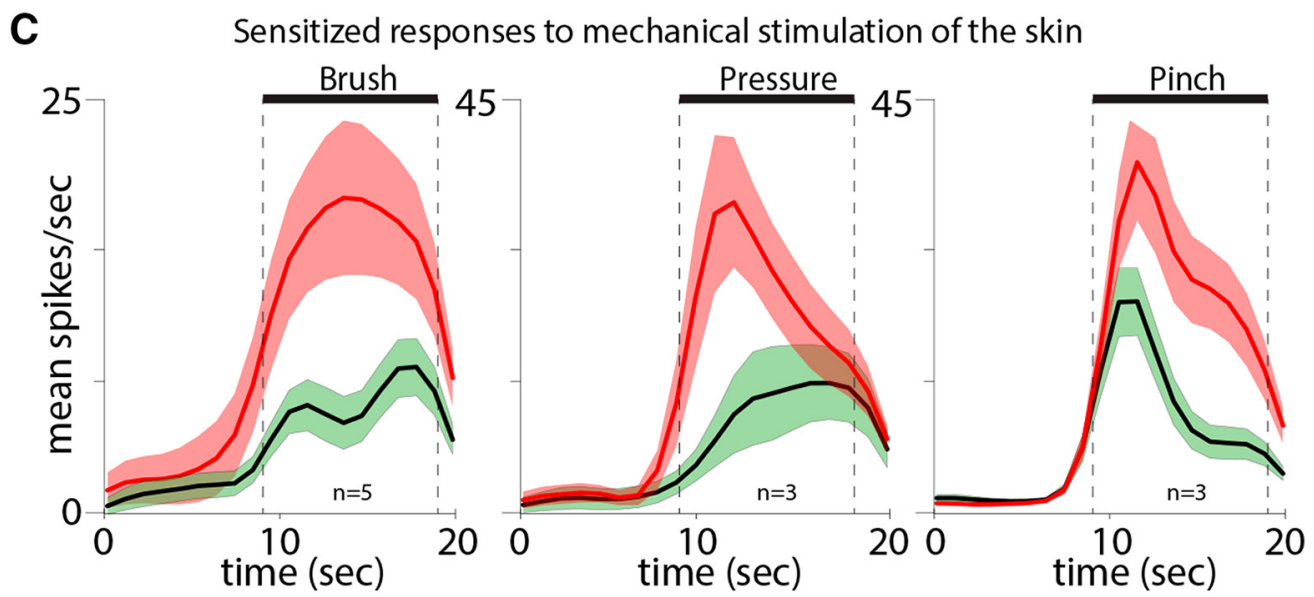

Figure 9. Neuronal responses of sensitized neurons to mechanical stimulation of $(\boldsymbol{A})$ the posterior dura, $(\boldsymbol{B})$ neck muscle, and $(\boldsymbol{C})$ skin (brush, pressure, and pinch) before ( $\mathrm{green})$ and $2 \mathrm{~h}$ after application of IS (red). Thick lines and shadowed areas represent mean and SE, respectively.

somatosensory processing and pain (Peyron et al., 2000; Saab and Willis, 2003; Apkarian et al., 2005; Borsook et al., 2008). To this extent, there are currently $>50$ pain imaging studies in which a clear activation signal is seen in the cerebellum (for review, see Moulton et al., 2010), and a few animal studies in which nociceptive stimuli applied to several body regions and organs trigger distinct activation of cerebellar neurons (Ekerot et al., 1987a,b; Ness et al., 1998; Saab and Willis, 2001). If migraine headache alters cerebellar function (Wang et al., 2016) in a way that is similar to the way it is thought to alter sensory processing in the cerebral cortex (May, 2003; Sprenger and Borsook, 2012), or if cerebellar neurons are not spared of the genetic tendency toward neuronal hyperexcitability of the migraine brain (Vincent and Hadjikhani, 2007), it may be reasonable to speculate that abnormally hyperexcitable cerebellar cortex can contribute to activation of meningeal nociceptors in a way shown previously at the cerebral cortex (Zhang et al., 2010, 2011). Along this line, it is worthy of our attention to consider the possibility that common cerebellar-mediated migraine symptoms such as vertigo, motion sickness, decreased motor coordination, balance change, and nystagmus (Kuritzky et al., 1981; Toglia et al., 1981; Kayan and Hood, 1984; Cutrer and Baloh, 1992; Cho et al., 1995; Baloh, 1997; Sándor et al., 2001; Ishizaki et al., 2002; Harno et al., 2003; Vincent and Hadjikhani, 2007) may coincide more closely with occipital than frontal migraine headaches.

As for the sensitization of the central cervicovascular neurons and their enhanced responses to mechanical stimulation of neck muscles and occipital skin following brief stimulation of the posterior dura with inflammatory mediators, it is reasonable to propose that this centrally-mediated muscle allodynia may play a role in the commonly described neck muscle tenderness that develops after (rather than before) the onset of headache (TfeltHansen et al., 1981; Jensen et al., 1988) and that the allodynia that develops in the occipital skin may explain cases in which patients prefer to sleep in a sitting position because the skin in the back of their head is painful to the extent that it wakes them up if they sleep on their back (Blake et al., 2018). Previous work showed that stimulation of the greater occipital nerve or neck muscles can sensitize central trigeminovascular neurons responses to stimulation of the more anterior dura overlying the sinuses (Piovesan 
et al., 2001; Bartsch and Goadsby, 2002). Our present findings suggest that activation of posterior dural nociceptors intracranially can give rise to headache and muscle tenderness/pain through activation of branches of the same nerve rather than convergence of dural and muscle afferents on central trigeminovascular neurons. Additionally, the identification of the course of these C2 DRG axons can provide an anatomical framework for conceptualizing how sustained muscle tenderness (tension) could result in compression of passing axons of meningeal nociceptors leading to intracranial release of inflammatory mediators and the triggering of occipital headache. Such a scenario is a critical component in our attempt to provide a possible explanation for the tight and reciprocal association between occipital headache and muscle tenderness.

\section{References}

Akerman S, Holland PR, Goadsby PJ (2011) Diencephalic and brainstem mechanisms in migraine. Nat Rev Neurosci 12:570-584.

Apkarian AV, Bushnell MC, Treede RD, Zubieta JK (2005) Human brain mechanisms of pain perception and regulation in health and disease. Eur J Pain 9:463-484.

Aurora SK, Dodick DW, Turkel CC, DeGryse RE, Silberstein SD, Lipton RB, Diener HC, Brin MF (2010) OnabotulinumtoxinA for treatment of chronic migraine: results from the double-blind, randomized, placebocontrolled phase of the PREEMPT 1 trial. Cephalalgia 30:793-803.

Baloh RW (1997) Neurotology of migraine. Headache 37:615-621.

Bartsch T, Goadsby PJ (2002) Stimulation of the greater occipital nerve induces increased central excitability of dural afferent input. Brain 125: $1496-1509$.

Blake P, Nir RR, Perry CJ, Burstein R (2018) Tracking patients with chronic occipital headache after occipital nerve decompression surgery: a case series. Cephalalgia. Advance online publication. Retrieved September 14, 2018. doi: 10.1177/0333102418801585.

Bogduk N (2004) The neck and headaches. Neurol Clin 22:151-171.

Borsook D, Burstein R, Becerra L (2004) Functional imaging of the human trigeminal system: opportunities for new insights into pain processing in health and disease. J Neurobiol 61:107-125.

Borsook D, Moulton EA, Tully S, Schmahmann JD, Becerra L (2008) Human cerebellar responses to brush and heat stimuli in healthy and neuropathic pain subjects. Cerebellum 7:252-272.

Burstein R, Yamamura H, Malick A, Strassman AM (1998) Chemical stimulation of the intracranial dura induces enhanced responses to facial stimulation in brain stem trigeminal neurons. J Neurophysiol 79:964-982.

Burstein R, Jakubowski M, Garcia-Nicas E, Kainz V, Bajwa Z, Hargreaves R, Becerra L, Borsook D (2010) Thalamic sensitization transforms localized pain into widespread allodynia. Ann Neurol 68:81-91.

Chen YF, Bramley G, Unwin G, Hanu-Cernat D, Dretzke J, Moore D, Bayliss S, Cummins C, Lilford R (2015) Occipital nerve stimulation for chronic migraine-a systematic review and meta-analysis. PLoS One 10:e0116786.

Cho AA, Clark JB, Rupert AH (1995) Visually triggered migraine headaches affect spatial orientation and balance in a helicopter pilot. Aviat Space Environ Med 66:353-358.

Chouret EE (1967) The greater occipital neuralgia headache. Headache 7:33-34.

Cutrer FM, Baloh RW (1992) Migraine-associated dizziness. Headache 32: 300-304.

Diener HC, Dodick DW, Aurora SK, Turkel CC, DeGryse RE, Lipton RB, Silberstein SD, Brin MF (2010) OnabotulinumtoxinA for treatment of chronic migraine: results from the double-blind, randomized, placebocontrolled phase of the PREEMPT 2 trial. Cephalalgia 30:804-814.

Dilli E, Halker R, Vargas B, Hentz J, Radam T, Rogers R, Dodick D (2015) Occipital nerve block for the short-term preventive treatment of migraine: a randomized, double-blinded, placebo-controlled study. Cephalalgia 35:959-968.

Edmeads J (1988) The cervical spine and headache. Neurology 38:18741878.

Ekerot CF, Gustavsson P, Oscarsson O, Schouenborg J (1987a) Climbing fibres projecting to cat cerebellar anterior lobe activated by cutaneous A and C fibres. J Physiol 386:529-538.

Ekerot CF, Oscarsson O, Schouenborg J (1987b) Stimulation of cat cutane- ous nociceptive $\mathrm{C}$ fibres causing tonic and synchronous activity in climbing fibres. J Physiol 386:539-546.

Gilman S (2000) The spinocerebellar ataxias. Clin Neuropharmacol 23:296-303.

Harno H, Hirvonen T, Kaunisto MA, Aalto H, Levo H, Isotalo E, Kallela M, Kaprio J, Palotie A, Wessman M, Färkkilä M (2003) Subclinical vestibulocerebellar dysfunction in migraine with and without aura. Neurology 61:1748-1752.

Ishizaki K, Mori N, Takeshima T, Fukuhara Y, Ijiri T, Kusumi M, Yasui K, Kowa H, Nakashima K (2002) Static stabilometry in patients with migraine and tension-type headache during a headache-free period. Psychiatry Clin Neurosci 56:85-90.

Ito M (2006) Cerebellar circuitry as a neuronal machine. Prog Neurobiol 78:272-303.

Jensen K, Tuxen C, Olesen J (1988) Pericranial muscle tenderness and pressure-pain threshold in the temporal region during common migraine. Pain 35:65-70.

Jensen R, Rasmussen BK, Pedersen B, Olesen J (1993) Muscle tenderness and pressure pain thresholds in headache: a population study. Pain 52:193-199.

Johnston MM, Jordan SE, Charles AC (2013) Pain referral patterns of the C1 to C3 nerves: implications for headache disorders. Ann Neurol 74: $145-148$.

Kayan A, Hood JD (1984) Neuro-otological manifestations of migraine. Brain 107:1123-1142.

Keller JT, Saunders MC, Beduk A, Jollis JG (1985) Innervation of the posterior fossa dura of the cat. Brain Res Bull 14:97-102.

Kelman L (2005) Migraine pain location: a tertiary care study of $1283 \mathrm{mi}-$ graineurs. Headache 45:1038-1047.

Kerr RW (1961) A mechanism to account for frontal headache in cases of posterior-fossa tumors. J Neurosurg 18:605-609.

Kimmel DL (1961) Innervation of spinal dura mater and dura mater of the posterior cranial fossa. Neurology 11:800-809.

Kosaras B, Jakubowski M, Kainz V, Burstein R (2009) Sensory innervation of the calvarial bones of the mouse. J Comp Neurol 515:331-348.

Kuritzky A, Toglia UJ, Thomas D (1981) Vestibular function in migraine. Headache 21:110-112.

Liveing E (1873) On megrim, sick headache. Nijmegen: Arts and Boeve.

May A (2003) Headache: lessons learned from functional imaging. Br Med Bull 65:223-234.

Melo-Carrillo A, Noseda R, Nir RR, Schain AJ, Stratton J, Strassman AM, Burstein R (2017) Selective inhibition of trigeminovascular neurons by fremanezumab: a humanized monoclonal anti-CGRP antibody. J Neurosci 37:7149-7163

Meyer EP, Beer GM, Lang A, Manestar M, Krucker T, Meier S, Mihic-Probst D, Groscurth P (2007) Polyurethane elastomer: a new material for the visualization of cadaveric blood vessels. Clin Anat 20:448-454

Moulton EA, Schmahmann JD, Becerra L, Borsook D (2010) The cerebellum and pain: passive integrator or active participator? Brain Res Rev 65:14-27.

Ness TJ, Follett KA, Piper J, Dirks BA (1998) Characterization of neurons in the area of the medullary lateral reticular nucleus responsive to noxious visceral and cutaneous stimuli. Brain Res 802:163-174.

Noseda R, Burstein R (2013) Migraine pathophysiology: anatomy of the trigeminovascular pathway and associated neurological symptoms, cortical spreading depression, sensitization, and modulation of pain. Pain 154:S44-S53.

Noseda R, Bernstein CA, Nir RR, Lee AJ, Fulton AB, Bertisch SM, Hovaguimian A, Cestari DM, Saavedra-Walker R, Borsook D, Doran BL, Buettner C, Burstein R (2016) Migraine photophobia originating in cone-driven retinal pathways. Brain 139:1971-1986.

Olesen J (1978) Some clinical features of the acute migraine attack: an analysis of 750 patients. Headache 18:268-271.

Paemeleire K, Bartsch T (2010) Occipital nerve stimulation for headache disorders. Neurotherapeutics 7:213-219.

Paemeleire K, Van Buyten JP, Van Buynder M, Alicino D, Van Maele G, Smet I, Goadsby PJ (2010) Phenotype of patients responsive to occipital nerve stimulation for refractory head pain. Cephalalgia 30:662-673.

Palmisani S, Al-Kaisy A, Arcioni R, Smith T, Negro A, Lambru G, Bandikatla V, Carson E, Martelletti P (2013) A six year retrospective review of occipital nerve stimulation practice: controversies and challenges of an 
emerging technique for treating refractory headache syndromes. J Headache Pain 14:67.

Penfield W, McNaughton F (1940) Dural headache and innervation of the dura mater. Arch Neurol Psychiat 44:43-75.

Peyron R, Laurent B, García-Larrea L (2000) Functional imaging of brain responses to pain: a review and meta-analysis. Neurophysiol Clin 30:263-288.

Piovesan EJ, Kowacs PA, Tatsui CE, Lange MC, Ribas LC, Werneck LC (2001) Referred pain after painful stimulation of the greater occipital nerve in humans: evidence of convergence of cervical afferences on trigeminal nuclei. Cephalalgia 21:107-109.

Ray BS, Wolff HG (1940) Experimental studies on headache. pain-sensitive structures of the head and their significance in headache. Arch Surg 41:813-856.

Saab CY, Willis WD (2001) Nociceptive visceral stimulation modulates the activity of cerebellar Purkinje cells. Exp Brain Res 140:122-126.

Saab CY, Willis WD (2003) The cerebellum: organization, functions and its role in nociception. Brain Res Brain Res Rev 42:85-95.

Sándor PS, Mascia A, Seidel L, de Pasqua V, Schoenen J (2001) Subclinical cerebellar impairment in the common types of migraine: a threedimensional analysis of reaching movements. Ann Neurol 49:668-672.

Schmahmann JD (1991) An emerging concept. the cerebellar contribution to higher function. Arch Neurol 48:1178-1187.

Schmahmann JD (1996) From movement to thought: anatomic substrates of the cerebellar contribution to cognitive processing. Hum Brain Mapp 4:174-198.

Schmahmann JD (2004) Disorders of the cerebellum: ataxia, dysmetria of thought, and the cerebellar cognitive affective syndrome. J Neuropsychiatry Clin Neurosci 16:367-378.

Schueler M, Messlinger K, Dux M, Neuhuber WL, De Col R (2013) Extracranial projections of meningeal afferents and their impact on meningeal nociception and headache. Pain 154:1622-1631.

Schueler M, Neuhuber WL, De Col R, Messlinger K (2014) Innervation of rat and human dura mater and pericranial tissues in the parieto-temporal region by meningeal afferents. Headache 54:996-1009.

Sjaastad O, Fredriksen TA (2000) Cervicogenic headache: criteria, classification and epidemiology. Clin Exp Rheumatol 18:S3-S6.

Sprenger T, Borsook D (2012) Migraine changes the brain: neuroimaging makes its mark. Curr Opin Neurol 25:252-262.

Stoodley CJ, Schmahmann JD (2009) Functional topography in the human cerebellum: a meta-analysis of neuroimaging studies. Neuroimage 44:489-501.

Strassman AM, Potrebic S, Maciewicz RJ (1994) Anatomical properties of brainstem trigeminal neurons that respond to electrical stimulation of dural blood vessels. J Comp Neurol 346:349-365.

Tang Y, Kang J, Zhang Y, Zhang X (2017) Influence of greater occipital nerve block on pain severity in migraine patients: a systematic review and meta-analysis. Am J Emerg Med 35:1750-1754.

Tfelt-Hansen P, Lous I, Olesen J (1981) Prevalence and significance of muscle tenderness during common migraine attacks. Headache 21:49-54.

Headache Classification Committee of the International Headache Society (2013) The International Classification of Headache Disorders: 3rd edition (beta version). Cephalalgia 33:627-808.

Toglia JU, Thomas D, Kuritzky A (1981) Common migraine and vestibular function. electronystagmographic study and pathogenesis. Ann Otol Rhinol Laryngol 90:267-271.

Vecchia D, Pietrobon D (2012) Migraine: a disorder of brain excitatoryinhibitory balance? Trends Neurosci 35:507-520.

Vincent M, Hadjikhani N (2007) The cerebellum and migraine. Headache 47:820-833.

Wang JJ, Chen X, Sah SK, Zeng C, Li YM, Li N, Liu MQ, Du SL (2016) Amplitude of low-frequency fluctuation (ALFF) and fractional ALFF in migraine patients: a resting-state functional MRI study. Clin Radiol 71:558-564.

Watkins JS (1969) Paroxysmal headache due to the chiari malformation. Dis Nerv Syst 30:693-695.

Welch KM (2003) Contemporary concepts of migraine pathogenesis. Neurology 61:S2-S8.

Yang Y, Song M, Fan Y, Ma K (2016) Occipital nerve stimulation for migraine: a systematic review. Pain Pract 16:509-517.

Zhang H, Yang X, Lin Y, Chen L, Ye H (2018) The efficacy of greater occipital nerve block for the treatment of migraine: a systematic review and meta-analysis. Clin Neurol Neurosurg 165:129-133.

Zhang X, Levy D, Noseda R, Kainz V, Jakubowski M, Burstein R (2010) Activation of meningeal nociceptors by cortical spreading depression: implications for migraine with aura. J Neurosci 30:8807-8814.

Zhang X, Levy D, Kainz V, Noseda R, Jakubowski M, Burstein R (2011) Activation of central trigeminovascular neurons by cortical spreading depression. Ann Neurol 69:855-865. 